\title{
Dinámica de cambios en el patrón de asentamiento de la Población Rural: Región del Maule
}

\author{
Margarita Riffo Rosas \\ Departamento de Geografía \\ Facultad de Arquitectura y Urbanismo, Universidad de Chile \\ mriffo@uchile.cl

\section{Carol Retamales Villa} \\ Escuela de Geografía \\ Facultad de Arquitectura y Urbanismo, Universidad de Chile \\ cretavil@gmail.com
}

\begin{abstract}
RESUMEN
Este artículo da cuenta de algunos de los resultados obtenidos del Proyecto de Investigación DI-U. Chile MULT 04/29-2 (2005-2006). En esta oportunidad, se analizan los cambios experimentados en el patrón de asentamiento de la población rural en tres comunas de la Región del Maule, como consecuencia del proceso de reasentamiento y concentración de la población rural en villorrios agrícolas surgidos en el contexto de la Globalización de la Economía con el apoyo del Estado a través de su Política de Vivienda Social. Como información base se utilizan los datos censales de 1992 y 2002 a través del Programa Redatam; la Cartografía regular del Instituto Geográfico Militar; el Listado de Villorrios proporcionado por la Dirección de Obras de cada Municipio y su constatación en terreno, además de la información levantada a través de entrevistas y encuestas.
\end{abstract}

Palabras Clave: Globalización - Población Rural - Patrones de Localización - Villorrios rurales.

\section{Dinamic changes in the pattern of establishment of the rural population: Región del Maule}

\begin{abstract}
This paper deals with some of the results of the DI-U .Chile MULT 04/29-2 research project (2005-2006). The changes in the settling pattern experienced in three counties in the Maule Region are analysed. This is a resettling and rural population concentration process empowered by the Globalization of the Economy and the support of the state through social housing policies. The data base is taken from the 1992 and 2002 population census through the Redatam Program, the Cartography from the Instituto Geográfico Militar, the List of villages provided by each city hall along with a field visit, besides information collected through interviews and questionaires.
\end{abstract}

Key words: Globalization - Rural Population - Localization Patterns - Rural Villages. 


\section{INTRODUCCIÓN}

Los asentamientos humanos de América Latina han sido caracterizados históricamente por una fuerte concentración de la población en pocos centros urbanos, en tanto las áreas rurales se distinguen como territorios altamente sub-ocupados predominando en ellas un patrón disperso de la población, representado por las economías campesinas.(de Mattos, 1979)

El proceso de urbanización latinoamericano ha sido sustentado básicamente por el aporte migratorio del sector rural, el que ha ido perdiendo gradualmente importancia demográfica en el tiempo, derivado fundamentalmente del rol subsidiario que las áreas rurales desempeñaron durante el período de industrialización sustitutiva.

El proceso de urbanización muestra un patrón desequilibrado entre los diversos asentamientos poblados, evidenciando un crecimiento alométrico de la población urbana en algunas ciudades de carácter primado, destacando entre ellas las capitales nacionales, las cuales han comandado a su vez el crecimiento económico de los respectivos países.

Los factores que explican esta situación, son tanto de carácter público como privado. Entre los primeros pueden señalarse las políticas macroeconómicas implementadas en la región desde 1930 , tendientes a lograr la integración territorial y económica de los países a través de la unificación de los mercados internos de productos y factores, articulando las regiones (y sus materias primas) con los centros urbanos donde se concentraban los establecimientos industriales del país.

A su vez, las decisiones y acciones de los actores del sector privado han estado condicionadas por las características del patrón territorial existente, privilegiando la localización de las inversiones en los sectores secundario y terciario de los asentamientos urbanos principales, reforzando con ello su rol como centros económicos y poblacionales de primer orden y a su vez las desigualdades regionales pre-existentes. Sin embargo, en las últimas décadas se observa en la región un decaimiento de esta tendencia, especialmente en lo relativo al crecimiento demográfico de los principales centros urbanos, en tanto las ciudades intermedias experimentan una dinámica creciente al respecto.

En Chile, aunque en forma más tardía que en el resto de América Latina, se ha impuesto este nuevo patrón de crecimiento entre los asentamientos urbanos, donde las ciudades regionales están concentrando el mayor crecimiento en desmedro de las ciudades primadas. Las razones para ello son variadas, destacando entre ellas las deseconomías observadas en las grandes metrópolis, lo cual se expresa en los mayores valores y escasez de suelo urbano, la contaminación ambiental, la congestión del transporte y la inseguridad ciudadana, todo lo cual finalmente se traduce en una pérdida de la calidad de vida de la población que habita en las grandes ciudades. (Romero, Toledo, 2000)

Las ciudades intermedias a su vez, están capitalizando al parecer los beneficios derivados de la dinámica de sus respectivos hinterlands, considerando que las regiones han sido valorizadas en el nuevo modelo en función de sus ventajas comparativas de carácter natural que favorecen el desarrollo de actividades primarias orientadas hacia los mercados externos (fruticultura, silvicultura, pesca, minería), desplazando gradualmente en importancia a la industria, tanto en la estructura de las exportaciones como en el proceso de sustitución de importaciones.

Otro fenómeno que se destaca en Chile a nivel regional en las últimas décadas, es el proceso de reasentamiento de la población rural como efecto de la modernización productiva de las estructuras económicas y la especialización resultante, lo que se expresa en el fortalecimiento de los núcleos rurales pre-existentes (como caseríos o aldeas) y muy especialmente por la formación de nuevos y pequeños asentamientos poblados, llamados localmente villorrios por sus habitantes, los cuales han surgido en función del 
apoyo de las políticas de vivienda social del Estado, que apuntan por una parte, a mejorar las condiciones de vida de la población rural mediante la urbanización de las áreas de concentración demográfica y por otra, a retener a la población en sus áreas de origen, atenuando con ello el éxodo hacia las ciudades. (Riffo, 1998).

Los villorrios están conformados por pobladores rurales sin tierras productivas, los que constituyen gran parte de la fuerza de trabajo de las actividades modernas, como fruticultura y silvicultura, y que mediante postulaciones colectivas pueden acceder a la vivienda propia y a través de ella a los servicios básicos asociados (agua potable, electricidad, eliminación de excretas), lo que ha viabilizado el proceso de urbanización en las áreas rurales, al igual que el fenómeno vinculado a la conformación de Parcelas de Agrado y Condominios rurales.

La concentración de la población bajo las dos modalidades señaladas, implica un cambio en los patrones de asentamiento rural, lo cual será objeto de análisis en el presente trabajo, focalizando el interés en la formación y localización espacial de los núcleos rurales conformados con el aporte del Estado -los villorrios agrícolas- y corresponde a los resultados de una investigación que fue desarrollada en el contexto del Proyecto DI - U.Chile MULT 04/29-2 finalizado en marzo 2007.

El estudio tiene como objetivo general dar cuenta de los cambios experimentados en los patrones de asentamiento espacial de la población rural en las comunas de Curicó, Romeral y Sagrada Familia, en la Provincia de Curicó de la Región del Maule, para detectar las tendencias de concentración de la población rural al interior de estas comunas y la incidencia en ello de los Villorrios Agrícolas conformados con apoyo del Estado en las últimas décadas.

\section{METODOLOGÍA}

La Región del Maule fue seleccionada considerando su alto Índice de Ruralidad (33,6\% en el año 2002) y su importancia frutícola a nivel nacional, ya que con 35.221 ha. plantadas, ocupa el tercer lugar en jerarquía (VI Censo Nacional Agropecuario, INE 1997). Como áreas específicas de estudio fueron seleccionadas tres comunas de la Provincia de Curicó, la que a su vez presenta una mayor especialización frutícola a nivel regional (56\%): una comuna de tipo urbano (Curicó con $16 \%$ de ruralidad en 2002) y dos comunas altamente ruralizadas (Sagrada Familia y Romeral, con $71 \%$ ). Las unidades de análisis son los Villorrios Agrícolas conformados con apoyo del Programa de Subsidio Habitacional Rural en cada comuna (63 en total).

En la primera parte, se procede a analizar la evolución de las entidades rurales existentes al interior de cada comuna en los registros censales de 1992 y del 2002, poniendo especial énfasis en las entidades con categoría de Aldea o Caserío, que son aquellas a las que el Instituto Nacional de Estadísticas (INE) asimila los villorrios agrícolas, dadas las características de poblamiento de estos asentamientos. La información utilizada en esta etapa es la incluida en la Base de Datos Redatam de ambos Censos.

Posteriormente, se procede a identificar las entidades con categoría de Aldea y Caserío que corresponden efectivamente a Villorrios Agrícolas, para lo cual se utilizó el Catastro de Villorrios confeccionado durante el desarrollo de la investigación a partir del listado proporcionado por los respectivos municipios y su constatación en terreno, donde entre otros datos se señala el año de formación de estos núcleos.

Lo anterior tiene como objeto identificar los sectores en donde se forman los primeros villorrios y las tendencias de concentración 
o dispersión de este tipo de asentamientos en las tres comunas consideradas, que se dan como consecuencia del surgimiento de nuevos villorrios agrícolas.

En la segunda parte y establecida la relación entre entidades y villorrios, se analiza la incidencia de la población concentrada en los villorrios en el total rural de la comuna en general y en Aldeas y Caseríos en especial, a objeto de dimensionar el nivel de concentración de la población rural en cada comuna. En este aspecto se trabajó con los resultados de las encuestas aplicadas en terreno a una muestra del $15 \%$ de las viviendas de los villorrios, donde se constata una estimación de 5,5 habitantes promedio por vivienda, que relacionado con el total de ellas en cada villorrio, determina la población estimada en cada uno de estos asentamientos.

\section{Figura $N^{\circ} 1$ : Esquematización de la Metodología aplicada}

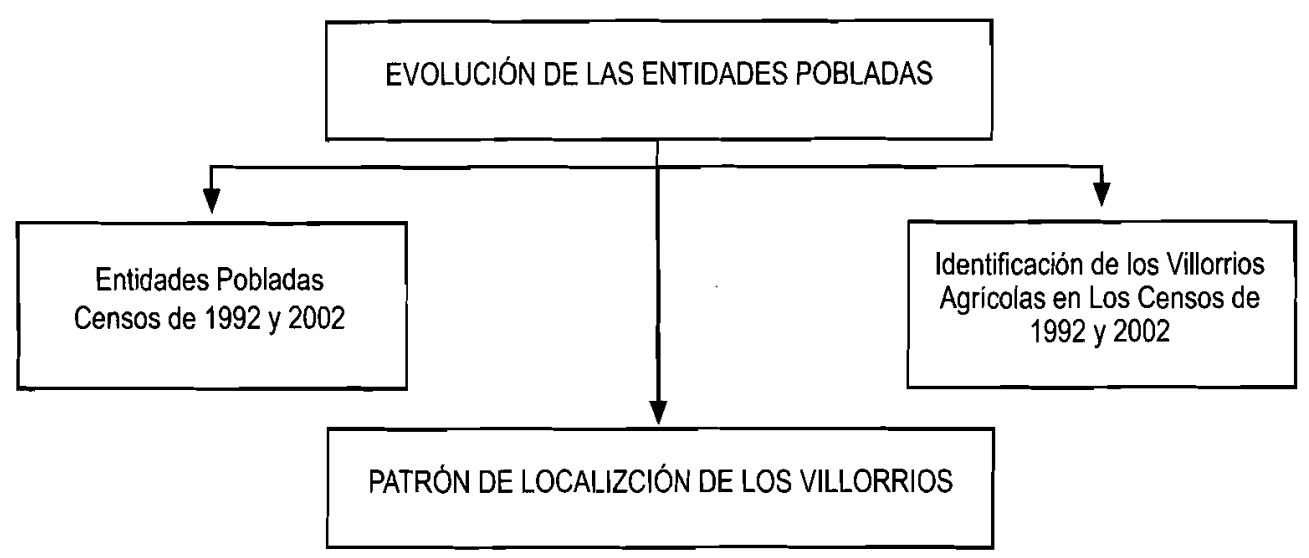

Fuente: Elaboración propia.

\section{ANTECEDENTES GENERALES}

\section{La Evolución del Patrón de Asentamiento de la Población Rural de Chile}

La evolución de los asentamientos de población en general, se vinculan a procesos más amplios referidos al cambio económico y social registrado en cada país. Ello significa que las formas de ocupación, organización, acondicionamiento y utilización del espacio están históricamente condicionadas por las características de la producción y sus implicancias en las estructuras sociales y que el patrón de asentamiento característico de una sociedad determinada es un subproducto del estilo de desarrollo predominante en ella (Jordán, 1987). Ello implica que la distribución de la población en las áreas rurales y las características de los asentamientos dependen en gran medida de la dinámica experimentada por el sector silvoagropecuario, de acuerdo al rol asignado a las áreas rurales en los modelos económicos de cada país.

Este planteamiento es especialmente válido en los países en desarrollo, por cuanto en ellos la formulación de políticas expresas de asentamiento, tanto en materia de ordenamiento territorial como de mejoramiento del hábitat, debe hacerse en condiciones de extrema pobreza y bajo la presión de un crecimiento demográfico acelerado.

En términos generales, el patrón histórico de poblamiento en las áreas rurales latinoamericanas ha sido de tipo disperso, vinculado a la existencia de las economías campesinas, coexistiendo con pequeños núcleos de concentración en pueblos y aldeas que operan como centros de servicios para su área circundante. 
En Chile, este patrón ha ido evolucionando gradualmente a medida que los espacios rurales han ido experimentando cambios estructurales significativos a través de la historia del agro.

En el periodo Hacendal (que se extiende hasta la década del 60 ), a la población campesina dispersa y los pequeños núcleos poblados, se agrega el agrupamiento interno de población dentro de las grandes haciendas agrícolas de Chile Central, representado por los llamados inquilinos, trabajadores permanentes de los predios que vivían con sus familias dentro de ellos, disponiendo de la regalía de la casa y un pequeño terreno de usufructo privado.

Con el proceso de Reforma Agraria (19671973), el inquilinato desaparece como forma de empleo y asentamiento, al subdividirse las grandes haciendas por expropiación del Estado. Los inquilinos son reubicados laboralmente en los llamados Asentamientos de la CORA (Corporación de la Reforma Agraria) y residencialmente en los Villorrios CORA, creados especialmente para tal efecto. Este proceso que culminó con la campesinización mediante la asignación de títulos de propiedad de parcelas individuales y sitios para la vivienda familiar, implicó por una parte, la formación de asentamientos de tipo lineal en torno a ejes de caminos donde se ubicaban los sitios residenciales y por otra, el comienzo de la modernización productiva del agro chileno a partir de las "reservas" a cargo de los propietarios de las antiguas haciendas que conservaron como propiedad individual.

En el periodo actual de Modernización Rural a partir de la década del 80 , que se orienta a la exportación de productos silvoagropecuarios con ventajas comparativas, se observa un proceso activo de descampesinización que ha afectado tanto a parceleros de la Reforma Agraria como a campesinos tradicionales que han transferido sus predios en el contexto de una mayor dinámica del mercado de tierras, por valorización de los distintos atributos de tipo agroclimático que favorecen el desarrollo de las actividades horto - frutícolas $\mathrm{y}$ forestales.
En este proceso se acrecienta en los campos, chilenos el segmento de los pobladores rurales sin tierras, los que a diferencia de los campesinos o pobladores rurales con tierras productivas, disponen solo de su fuerza de trabajo como factor de producción para la supervivencia familiar (Rivera y Cruz, 1984). A diferencia de décadas anteriores, donde el éxodo rural dinamizó el proceso de urbanización y consolidación de las grandes ciudades chilenas, unido al proceso de "industrialización sustitutiva", los pobladores rurales sin tierras han permanecido en sus áreas de origen, primero como "allegados" de familiares o amigos y posteriormente como habitantes de los nuevos asentamientos poblados llamados villorrios, que han surgido en función de la Política de Vivienda Social del Estado y las opciones de empleo, aunque temporal, en las actividades modernizadas del sector rural.

De esta forma, parte de estos pobladores rurales sin tierra han transitado en el tiempo y en el espacio desde una situación de inquilinos de las antiguas haciendas agrícolas, que en la década del 60 fueron expropiadas por el Estado, hacia una nueva categoría social en el campo constituida por los parceleros de la Reforma Agraria en la década del 70, y luego desde los años 80, hacia el componente de los pobladores rurales sin tierra, en razón de la transferencia de sus parcelas dentro de la dinámica del mercado resultante del actual proceso de modernización.

El surgimiento de los villorrios como nuevos asentamientos poblados en el campo chileno, constituye un fenómeno de reciente data, que implica por una parte, un cambio gradual en el patrón de asentamiento de la población, desde el disperso representado por las economías campesinas, al concentrado en pequeños núcleos de concentración dispersa. Por otra parte, el material constructivo y el diseño arquitectónico de las viviendas construidas por las empresas inmobiliarias dedicadas al sector social, presentan un marcado sesgo urbano que no se relaciona con la típica vivienda campesina chilena de adobe, todo lo cual rompe con el perfil del paisaje rural tradicional (Riffo, Retamales, 2005). 


\section{MARCO TEÓRICO REFERENCIAL}

Los espacios rurales tradicionales de América Latina han sido definidos en función de las características del poblamiento y la ocupación de sus habitantes, asumiendo que predomina un patrón disperso de la población representado por el sector campesino, junto con el desarrollo de actividades fundamentalmente primarias, orientadas a la producción de alimentos y materias primas para la población e industrias situadas en áreas urbanas, además de subsidiar con mano de obra barata las actividades secundarias y terciarias.

Sin embargo y de acuerdo a la Teoría del Dualismo Estructural, en dicho contexto funcional las oportunidades de desarrollo efectivo han sido restrictivas para las áreas rurales, constituyendo un sector atrasado con respecto a las ciudades, lo que explicaría el éxodo campo - ciudad con el consiguiente despoblamiento rural, proceso que acompaña todo el período de industrialización sustitutiva (Sili, 2002).

En la actualidad a partir de los 80 y en el marco de la globalización, las áreas rurales han pasado a desempeñar un rol protagónico en la economía, con la capitalización y modernización de las actividades que presentan ventajas comparativas en los mercados internacionales, reafirmando el papel de las regiones a partir de la desconcentración espacial de las actividades; más que integradas al contexto nacional en función de los mercados internos, las regiones deben ser capaces de integrarse a la economía mundial, generando recursos y empleo para sustentar su propio desarrollo, de modo que la población rural sea retenida en sus áreas de origen, mejorando sus condiciones de vida y mitigando con ello el éxodo hacia las ciudades.

La industrialización de la agricultura, particularmente visible a partir de los 90 , introduce una inflexión importante al fracturar el mundo rural en dos realidades bien distintas: el sector rural moderno y el sector rural tradicional y por consecuencia, la oposición campo-ciudad deja paso al Dualismo Intra-rural, con una nueva dicotomía que se instaura al interior del sector (Sili, 2002).

Esta nueva realidad modifica la visión que se tenía del sector rural. En la actualidad, se le valora como reserva de recursos naturales y paisajes; se le relaciona con el medio ambiente y la calidad de vida; se le visualiza como alternativa a la concentración urbana; se le valoriza en su vínculo con equilibrios regionales y se le considera universo de actividades multisectoriales (Echenique, 2001). Como consecuencia, el mundo rural deja de organizarse en torno a la clásica tetralogía de caracterización, esto es, producir alimentos para la población y la industria urbana, la agricultura como actividad dominante y el sector campesino como grupo social de referencia, junto con un tipo de paisaje que refleja un equilibrio entre la naturaleza y las actividades humanas allí desarrolladas (Ferrao, 2000).

La nueva agricultura orientada fuertemente a la exportación y caracterizada por una modernización empresarial y tecnológica, ha generado nuevas demandas y modalidades de trabajo, que hipotéticamente han frenado o revertido los procesos migratorios del campo. Así, la agricultura moderna es capaz de generar un nuevo diálogo entre el campo y la ciudad, por cuanto lejos de expulsar población, la importa, frenando e incluso revirtiendo los flujos migratorios del pasado. La modernización productiva conlleva problemas sociales ligados a la reasignación laboral y sobretodo geográfica de importantes contingentes de población, lo cual se acompaña de cambios en la tenencia de la tierra, en los usos del suelo, en la modalidad del empleo y en nuevas relaciones laborales, todo lo cual genera simultáneamente movimientos de población o de mano de obra, creación de nuevos asentamientos rurales y decrecimiento de otros (Daher, 1987).

El boom modernizador impacta en los asentamientos rurales tanto en el plano habita- 
cional como en infraestructura y servicios. Se asiste a un proceso de repoblamiento rural bajo la forma de una urbanización del campo y no a costa del campo. Este cuadro de relocalización demográfica, es acompañado además por una localización marcadamente territorial y una transformación del sistema de asentamientos humanos en el interior del sector rural.

En rigor, este proceso es todavía una suburbanización en su doble acepción: en tanto periférica o satelizada frente a los centros urbanos locales y en cuanto a infraestructura en su nivel de equilibrio social.

El proceso de agrourbanización descrito, es marcadamente determinado y acelerado por el fomento de las actividades exportadoras y la orientación hacia afuera del sector rural y no solo la nueva agricultura refleja esta dirección, por cuanto la urbanización correlacionada con ello tiene en su origen el rótulo de su destino "for export" (Daher, 1987).

El primer movimiento demográfico que se observa en este proceso es en las llamadas áreas periurbanas, que se constituyen en una frontera de cambios sociales y paisajes y donde el uso residencial sustituye gradualmente el uso productivo del suelo, en una clara demostración de la extensión de la ciudad sobre el campo, una "urbanización difusa" que expresa el interés de pobladores de origen urbano por relocalizar su residencia en áreas rurales, conformando verdaderos corredores residenciales en torno a las autopistas que conectan con la ciudad, habitados por conmuters (conmutadores) que viven en el campo pero trabajan en la ciudad, por lo que no se observa correlación entre la distancia en línea recta desde un área urbana y el grado de ruralidad, ya que las autopistas han aumentado la distancia que estos residentes están dispuestos a recorrer diariamente a través de movilización propia (Clouth, 1976).

La competencia por los nuevos usos del suelo rural, generados por las actividades residenciales, industriales y turísticas frente a los usos silvoagropecuarios, es un fenómeno que se inicia en los países desarrollados después de la segunda post guerra y parte con el reconocimiento de las malas condiciones ambientales en las grandes ciudades junto con la construcción de modernas autopistas, lo que permitió primeramente el establecimiento de residencias secundarias de fin de semana o de vacaciones y posteriormente residencias permanentes, en la medida que la jornada de trabajo se reduce a menos días laborales aumentando con ello el tiempo de ocio, proceso que ha sido conceptualizado como Neo-ruralismo (García, et al, 1995).

Este fenómeno denominado también "exurbanización" contribuyó al asentamiento de grandes contingentes de población urbana en las áreas rurales, modificando su fisonomía tradicional, fenómeno que dista mucho de llegar a los países tercermundistas (Molinero, 1990).

Pero el fenómeno se instaló en Chile a partir de los 90 , y se expresa a través de la "Urbanización de elite" (Armijo, 2000), representada por parcelas de agrado y condominios rurales, siendo las primeras unidades residenciales de manejo individual y los condominios formados por varias parcelas que se administran en forma comunitaria, y que a diferencia de la anterior, se componen de predios de menor dimensión. Sin embargo, ambos tipos representan a personas de elevados ingresos y de origen urbano.

Estas urbanizaciones son fácilmente distinguibles en el paisaje rural porque conforman espacios característicos por el tipo de construcción de viviendas de elevada calidad y costo, junto a una sofisticada infraestructura recreacional (piscina, recintos deportivos, parques y jardines), además de la infraestructura básica pertinente (agua, electricidad, eliminación de excretas). Ambos tipos de urbanización conforman verdaderos enclaves residenciales de tipo urbano al interior del mundo rural, reproduciendo el fenómeno de segregación socio-espacial de las ciudades, siendo su vinculación con el hábitat cam- 
pesino circundante, referida solamente a la contratación de fuerza laboral en el rubro construcción y servicios (cuidadores, jardineros y asesoras del hogar) (Armijo, 2000).

Otra vertiente que refleja el avance de la urbanización del campo, es la que se expresa a través de la conformación de nuevos asentamientos rurales, denominados genéricamente Villorrios por sus habitantes, los cuales han surgido por iniciativa del Estado a través de su Política de Subsidio Habitacional Rural y por lo tanto, está orientada específicamente a los pobladores de origen rural y de bajos ingresos, con el objetivo de retenerlos en sus áreas de origen mejorando objetivamente sus condiciones de vida a través del acceso a la vivienda propia (nueva, sólida y sin deuda ulterior), junto a los servicios básicos que le están asociados (agua potable, electricidad, sistema de eliminación de excretas) y del equipamiento comunitario en salud, educación y transporte, aunque estos se ubiquen fuera del conjunto residencial, en "corredores de servicios" situados en los principales caminos de acceso a varios villorrios (Riffo, Retamales, 2005).

Desde la visión del Ministerio de Vivienda y Urbanismo (MINVU) y en términos de políticas públicas, desarrollo rural implica la existencia de infraestructura básica y social, caminos y vías de comunicación, pavimentación de calles y seguridad ambiental, y se habría estado dando una señal equívoca de que sólo en las ciudades era posible encontrar tales beneficios, lo que estimuló en el pasado el éxodo campo-ciudad (Hermosilla, 1994).

Para avanzar en este objetivo es clave que existan pequeños agrupamientos rurales, por cuanto es inviable económicamente llegar con soluciones individuales a la población dispersa en el sector rural. Por ello, era necesario estimular la concentración de la población del campo, a objeto de alcanzar umbrales mínimos que justifiquen las inversiones en urbanización.
En este contexto, la propuesta del MINVU es establecer Villas o Villorrios rurales que favorezcan la radicación y no la erradicación de los pobladores, permaneciendo en sus áreas de origen y manteniendo sus redes sociales de apoyo junto con el acceso al empleo en el entorno productivo (Riffo, Retamales, 2005).

Para estos efectos, el MINVU define los villorrios como "asentamientos humanos separados de la ciudad o centro urbano, de una extensión demográfica no superior a 2500 habitantes, dotados de infraestructura básica y social acorde al desarrollo de ellas en el país y con una o varias actividades productivas que aseguren fuentes laborales a sus habitantes". (MINVU, 1994)

Finalmente, una consideración indispensable para orientar este proceso es la de ampliar el concepto de lo rural más allá de lo campesino, para incluir a pescadores artesanales, pirquineros, y trabajadores temporeros de la silvicultura y fruticultura, los cuales conforman la estructura ocupacional del campo chileno.

\section{RESULTADOS}

\section{Comuna de Curicó}

Evolución de la población Rural Comuna de Curicó

La población total de Curicó ha experimentado un aumento constante y sostenido entre los años 1982 y 2002; este aumento se refleja en el crecimiento de la población urbana de la comuna que pasa de representar un $55 \%$ del total en 1982, a un $84 \%$ en el 2002. Por su parte, la población rural es inferior a la población urbana durante todo el periodo considerado y ha experimentado una significativa disminución, pasando de concentrar un $45 \%$ de la población total en 1982 a solo un $16 \%$ el año 2002 (Tabla $\mathrm{N}^{\circ} 1$ ). 
Dinámica de cambios en el patrón de asentamiento de la Población Rural: Región del Maule

Tabla No 1: Evolución de la Población Rural de la Comuna de Curicó

\begin{tabular}{c|c|c|c|c|c|c}
\hline \multirow{2}{*}{ AÑO } & \multicolumn{2}{|c|}{ RURAL } & \multicolumn{2}{c|}{ URBANA } & \multicolumn{2}{c}{ TOTAL } \\
\cline { 2 - 7 } & Número & Porcentaje & Número & Porcentaje & Número & Porcentaje \\
\hline 1982 & 39.014 & 45,0 & 47.684 & 55,0 & 119.585 & 100 \\
\hline 1992 & 23.770 & 33,0 & 80.345 & 67,0 & 100.506 & 100 \\
\hline 2002 & 19.079 & 16,6 & 100.506 & 84,0 & 19.079 & 100 \\
\hline
\end{tabular}

Fuente: Censos de Población y Vivienda 1982,1992 y 2002. (INE)

\section{Evolución de las Entidades Pobladas de la Comuna de Curicó}

Cada categoría de entidad da cuenta de un tipo especial de poblamiento, de este modo y dadas las características que las originan, las entidades rurales con categoría de caserío y aldea son las que revisten mayor importancia en este estudio, ya que a ellas son asimilados los villorrios rurales en los censos de Población y Vivienda.

La población urbana de la comuna se concentra en la ciudad de Curicó y en los tres pueblos que posee (Sarmiento, Los Niches y Tutuquén ), de los cuales, los dos últimos son asentamientos urbanos recientes, que se registran como tales sólo a partir del censo del 2002.

La importante disminución que experimentó la población rural de la comuna, se explica si se considera que al año 2002 en Curicó hay 78 entidades rurales menos que en 1992 , (55 de éstas corresponden a caseríos y 23 a parcelas), pese a lo cual el surgimiento de cuatro nuevas aldeas, un fundo y dos parcelas de agrado a las que se suman los dos nuevos pueblos, hacen que en el total de entidades solo se aprecie la disminución de 69 asentamientos entre los censos de 1992 y el 2002 (Tabla $\mathrm{N}^{\circ}$ 2).

Tabla No 2: Número de Entidades según categoría, Comuna de Curicó

\begin{tabular}{l|c|c|c}
\hline CATEGORIA & 1992 & 2002 & DIFERENCIA 1992/2002 \\
\hline Ciudad & 1 & 1 & 0 \\
\hline Pueblo & 1 & 3 & 2 \\
\hline Aldea & 7 & 11 & 4 \\
\hline Caserio & 106 & 51 & -55 \\
\hline Fundo & 118 & 119 & 1 \\
\hline Parcela & 129 & 106 & -23 \\
\hline Parcela de Agrado & 0 & 2 & 2 \\
\hline TOTAL & 362 & 293 & 69 \\
\hline
\end{tabular}

Fuente: Bases de Datos Redatam. Censos 1992 y 2002. (INE)

\section{Población Rural de Curicó concentrada en Entidades Pobladas}

Los datos de la tabla $\mathrm{N}^{\circ} 3$, muestran que en ambos censos más de la mitad de la población rural de la comuna se concentra en entidades con categoría de aldeas o caseríos.
Pese a que a nivel comunal la población rural de la comuna experimentó un descenso bastante significativo, la población rural que reside en entidades con categoría de Aldea o Caserío en términos porcentuales disminuyó sólo levemente, pasando de concentrar un $57,3 \%$ de la población total en 1992 a un $56,7 \%$ en el 2002. 
Tabla No 3: Población Rural de Curicó concentrada en Caseríos y Aldeas

\begin{tabular}{c|c|c|c|c|c|c}
\hline \multirow{2}{*}{ POBLACIÓN } & \multicolumn{3}{|c|}{1992} & \multicolumn{3}{|c}{2002} \\
\cline { 2 - 7 } & Total Rural & $\begin{array}{c}\text { En Caserios y } \\
\text { Aldeas }\end{array}$ & Porcentaje & Total Rural & $\begin{array}{c}\text { En Caseríos y } \\
\text { Aldeas }\end{array}$ & Porcentaje \\
\hline Hombres & 12.851 & 7.176 & 55.8 & 9.989 & 5.630 & 56.3 \\
\hline Mujeres & 10.919 & 6.460 & 59.1 & 9.090 & 5.191 & 57.1 \\
\hline TOTAL & 23.770 & 13.636 & 57.3 & 19.079 & 10.821 & 56.7 \\
\hline
\end{tabular}

Fuente: Bases de Datos Redatam. Censos 1992 y 2002. (INE)

Dado que no todos los caseríos y aldeas de la comuna corresponden a villorrios agrícolas, se calculó la población de los villorrios en base al promedio de habitantes por vivienda $(5,5)$ y el número de viviendas por villo- rrio obtenido en terreno. De acuerdo a esta información, la población rural que reside en villorrios agrícolas en la comuna de Curicó se estimó en 10.461 habitantes (Tabla $\mathrm{N}^{\circ} 4$ ).

\section{Tabla Nº: Población en Villorrios, Comuna de Curicó}

\begin{tabular}{l|c}
\hline Viviendas en Villorrios & 1.902 \\
\hline Habitantes por Viviendas $(\mathrm{P})$ & 5.5 \\
\hline Población Villorrios (E) & 10.461 \\
\hline
\end{tabular}

Fuente: Elaboración propia sobre la base de Encuesta aplicada en terreno (2002).

$\mathrm{P}=$ Promedio de Habitantes por vivienda. E= Estimación de población.

Tomando como base la población estimada de los villorrios, se constata que en Curicó un $54,82 \%$ de la población rural total y un
$96,67 \%$ de la población rural concentrada en Aldeas y Caseríos, corresponde a población residente en villorrios agrícolas (Tabla $N^{\circ} 5$ ).

Tabla Nº5: Participación de la población de los villorrios de la Comuna de Curicó

\begin{tabular}{l|c}
\hline Sobre la población & Porcentaje \\
\hline Rural Total & 54.82 \\
\hline En Caserios y Aideas & 96.67 \\
\hline
\end{tabular}

Fuente: Elaboración propia sobre la base de Censo de Población y Vivienda (INE 2002).

Los datos anteriores dan cuenta que un importante porcentaje de la población rural total y sobre todo de la población de los caseríos y aldeas de la comuna, corresponden a residentes de villorrios agrícolas, por lo que es pertinente entonces identificar cuáles de estas aldeas y caseríos son efectivamente villorrios agrícolas.

Identificación de los Villorrios de Curicó en los Censos de Población y Vivienda de 1992 y 2002
De acuerdo a las Bases de Datos Redatam del Censo de 1992, en Curicó existían 40 localidades pobladas dentro de las cuales se distribuyen un total de 362 entidades. 26 de las 40 localidades existentes a esa fecha, contienen entidades rurales con categoría de Aldea o Caserío.

Según las Bases de Datos Redatam del Censo del 2002, el número de localidades pobladas de Curicó disminuyó en 5 y el de entidades en 69 , es decir, actualmente tiene 35 localidades que contienen un total de 293 entidades 
pobladas. De las 35 localidades existentes, 27 corresponden a localidades con aldeas y caseríos, esto es, pese a que disminuye el número total de localidades aumenta en 1 el número de localidades gue contienen entidades con categoría de aldea o caserío.

La correcta identificación de los villorrios dentro de la comuna, exige considerar el año en el que éstos se formaron como tales, ya que cada villa tiene un año de origen distinto y por lo tanto, hay algunos más recientes que otros. De esta forma, es posible encontrar villorrios con más de 10 años de antigüedad y otros con menos y como es dable esperar, los asentamientos más recientes no aparecen en el censo de 1992 e incluso los más nuevos no existían al momento de realizarse el censo del 2002. Por esta razón se consideró que aquellos villorrios con más de 13 años de antigüedad deberían aparecer en ambos censos, aquellos con una antiguiedad superior a 4 años deberían estar contemplados solo en el censo 2002 y los villorrios de menos de 3 años de formación no deberían aparecer en ninguno, pues se conformaron con posterioridad a la realización del último censo.

Tabla N6: Año de antigüedad de los villorrios de Curicó

\begin{tabular}{cc|cc}
\hline Nombre del Villorrio & Año de Formación & Nombre del Villorrio & Año de Formación \\
\hline La Parroquia & 1980 & Santa Mónica & 1989 \\
\hline Villa Aurora & 1981 & Progreso 1 & 1990 \\
\hline La Palmera & 1981 & Vista Hermosa Norte & 1991 \\
\hline José Miguel Carrera & 1981 & Progreso 2 & 1991 \\
\hline Villa O'Higgins & 1981 & Villa Primavera & 1991 \\
\hline Villa Santa Marta & 1982 & San Alfonso & 1992 \\
\hline Santa Carmen & 1986 & El Prado & 1992 \\
\hline El Membrillo & 1986 & Los Marcos & 1992 \\
\hline Villa Macondo & 1988 & Cordillera & 1992 \\
\hline Julián Lozano & 1988 & San Martín de Las Piedras & 1992 \\
\hline Enrique Frolich & 1988 & Villa Cordillera & 1992 \\
\hline Los Guindos & 1989 & Prudencio Lozano & 1996 \\
\hline San Vicente & 1989 & Santa Filomena & 1996 \\
\hline Los Niches & 1989 & Nuevo Amanecer \\
\hline Santa Claudia & 1989 & & \\
\hline
\end{tabular}

Fuente: Entrevista aplicada en terreno (2002).

De acuerdo al año de formación de los villorrios, en el censo de 1992 deberían aparecer 20 de los 29 villorrios de la comuna de Curicó. La figura $\mathrm{N}^{\circ} 2$ muestra que en el censo de 1992 solo fueron considerados como entidades independientes 13 villorrios agríco- las, que corresponden a Los Guindos, Santa Carmen, Julián Lozano, Enrique Frolich, El Progreso 1, San Martín de las Piedras, Villa O'Higgins, La Parroquia, La Palmera, José Miguel Carrera, Villa Cordillera, Santa Marta y Santa Mónica. 
Figura N²: Mapa de Villorrios Agrícolas de Curicó según Censo de 1992

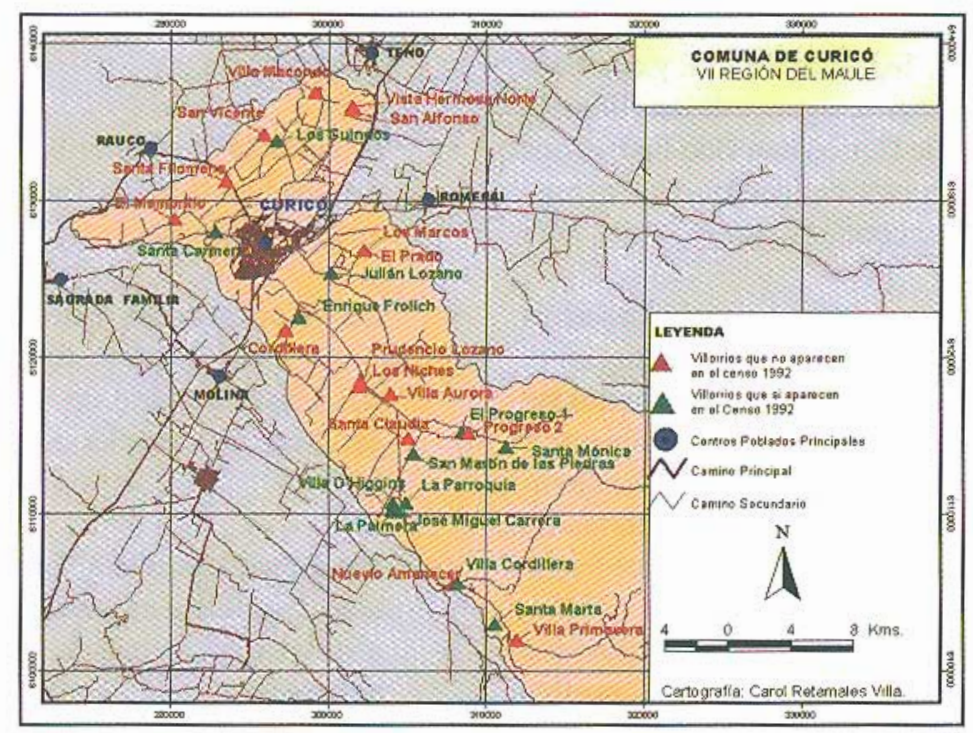

Fuente: Elaboración propia sobre la base de información (INE 1992).

Considerando el año de formación de los villorrios, en el censo del 2002 deberían aparecer como entidades independientes los 29 villorrios agrícolas de la comuna; $\sin$ embargo, la figura $\mathrm{N}^{\circ} 3$ muestra que solo aparecen 13 de ellos, que corresponden a
Los Guindos, Santa Carmen, Julián Lozano, Enrique Frolich, Santa Claudia, San Martín de las Piedras, Villa O’Higgins, la Parroquia, Villa Cordillera, Nuevo Amanecer, Santa Marta, Villa Primavera y Santa Mónica.

Figura $\mathrm{N}^{\circ}$ 3: Mapa de Villorrios Agrícolas de Curicó según Censo de 2002

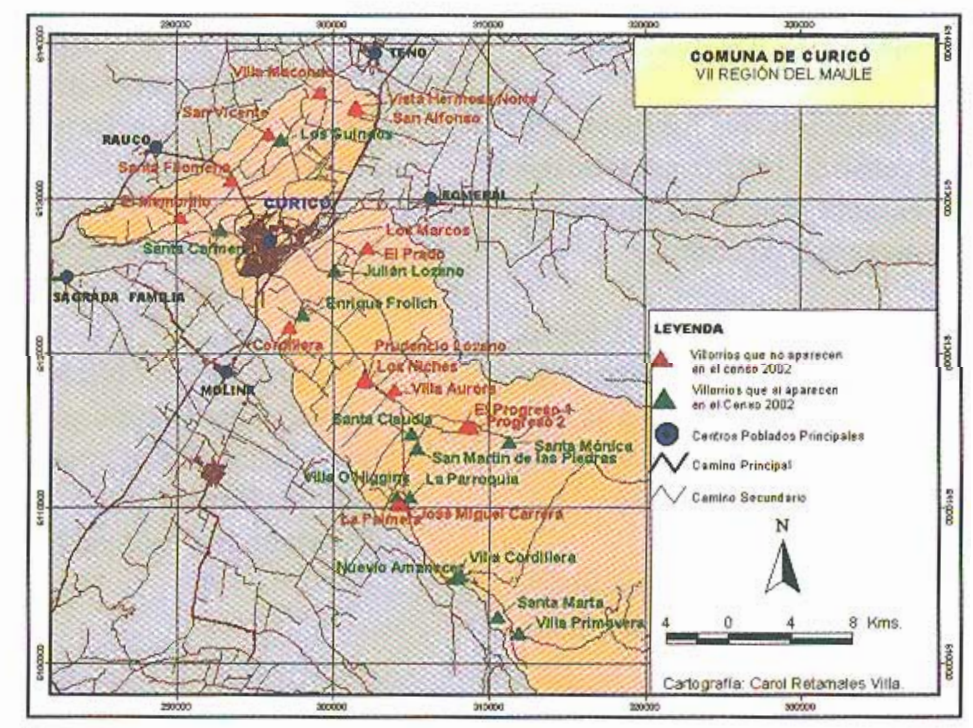

Fuente: Elaboración propia sobre la base de información INE (1992). 
La evolución de los villorrios a través del registro censal 1992 y 2002, da cuenta de que pese al origen independiente de estos asentamientos, bajo criterio INE y con fines estadísticos oficiales, algunos de los villorrios de la comuna de Curicó han sido fusionados dando origen a otra entidad que los agrupa bajo un nombre común.

Atendiendo al carácter de las entidades agrupadas, es posible reconocer dos situaciones distintas y ambas se deben a la proximidad geográfica existente entre los asentamientos; la primera de ellas corresponde a la fusión rural, que consiste en que dos o más entidades de carácter rural son agrupadas, conformando una sola entidad que adquiere un nombre común para todos los asentamientos que agrupa. La segunda situación que es posible reconocer corresponde a la absorción, y ésta se produce cuando una entidad mayor de carácter urbano absorbe a una o más entidades rurales debido a su proximidad geográfica; en este caso se pierde el nombre de las entidades menores y éstas pasan a formar parte de la entidad urbana, esto con fines estadísticos oficiales y a pesar de que los habitantes de la comuna las sigan identificando como independientes con su nombre original.

De acuerdo al Instituto Nacional de Estadística (INE), los casos de fusión rural detectados en Curicó corresponden a los siguientes:

- El villorrio Macondo, que fue fusionado tanto en el censo de 1992 como en el del 2002 a la entidad Rincón de Sarmiento que tiene categoría de caserío.

- La aldea Vista Hermosa, que se forma de la fusión del villorrio Vista Hermosa con otros caseríos aledaños y a la que con posterioridad al censo de 1992 se le suma el villorrio San Alfonso.

- El villorrio San Vicente que fue fusionado al caserío Santa Olga en ambos Censos.
- El villorrio Santa Filomena, que surge con posterioridad al censo de 1992, fue fusionado al caserío Callejón las Salinas.

- $\quad$ El villorrio El Membrillo, que aparece fusionado a la aldea Tutuquén Alto en ambos censos.

- De la unión de los villorrios El Prado y Los Marcos, que se forman con posterioridad al censo de 1992, surge el caserío Los Cristales en el censo del 2002.

- El villorrio Cordillera, forma parte de la aldea Cordillera en ambos censos, junto a dos caseríos que no son villorrios agrícolas.

- Villa Aurora fue fusionada a la aldea Santa Elena, en ambos censos.

- En 1992, el villorrio Progreso 2 no existía, por lo que el villorrio Progreso 1 estaba considerado como una entidad independiente con categoría de caserío. En el censo 2002 ambas entidades fueron agrupadas en la aldea El Progreso.

- Los villorrios La Palmera y José Miguel Carrera en 1992, fueron considerados como entidades independientes con categoría de caseríos. En el censo 2002 ambos pasaron a formar parte de la aldea La Palmera.

En situación de absorción se detectó el siguiente caso:

- El villorrio Los Niches aparece en ambos censos como parte del pueblo Los Niches. En el censo del 2002, el villorrio Prudencio Lozano también es absorbido por este pueblo. 


\section{Comuna de Romeral}

Evolución de la población Rural Comuna de Romeral

Pese a que la población rural de la comuna de Romeral es superior a la población urbana durante todo el periodo considerado y que en número absoluto ésta aumentara levemente, en términos porcentuales la población rural ha experimentado un descenso, pasando de concentrar $82,78 \%$ del total de población en 1982 a 71,08 \% el año 2002 (Tabla N ${ }^{\circ}$ 7).

Por su parte, la población urbana de la comuna ha aumentado levemente entre 1982 y el 2002, pese a lo cual, el año 2002 solo equivale al $28,92 \%$ de la población total.

Tabla $\mathbf{N}^{\circ}$ 7: Evolución de la Población Rural de la Comuna de Romeral

\begin{tabular}{c|c|c|c|c|c|c}
\hline \multirow{2}{*}{ AÑO } & \multicolumn{2}{|c|}{ RURAL } & \multicolumn{2}{c|}{ URBANA } & \multicolumn{2}{c}{ TOTAL } \\
\cline { 2 - 6 } & Número & Porcentaje & Número & Porcentaje & Número & Porcentaje \\
\hline 1982 & 8.386 & 82,78 & 1.745 & 17,22 & 10.131 & 100 \\
\hline 1992 & 9.015 & 78,46 & 2.475 & 21,54 & 11.490 & 100 \\
\hline $\mathbf{2 0 0 2}$ & 9.032 & 71,08 & 3.675 & 28,92 & 12.707 & 100 \\
\hline
\end{tabular}

Fuente: Censos de Población y Vivienda 1982,1992 y 2002. (INE)

Evolución de las Entidades pobladas de la comuna de Romeral

La tabla $N^{\circ} 8$ muestra que al año 2002 la comuna de Romeral posee 56 entidades menos que en el año 1992, situación que obedece a la disminución de 13 caseríos, 15 fundos y 31 parcelas.

La disminución de las entidades con categoría de caserío, puede explicarse si se considera que en la comuna a su vez surgen 3 nuevas aldeas que probablemente nacen de la fusión de los caseríos.
Por su parte, la disminución de fundos y parcelas, puede deberse al hecho de que al ser una comuna altamente especializada en la fruticultura, estos fundos y parcelas que desaparecen entre ambos censos, pudiesen haber sido comprados y pasado a formar parte de algún fundo ya existente o conformaran entre varios de ellos uno solo, con nombre común.

En ambos censos, la Comuna comprende una sola entidad de carácter urbana, que corresponde al pueblo de Romeral, capital comunal.

Tabla $\mathbf{N}^{\circ}$ 8: Número de Entidades según categoría, Comuna de Romeral

\begin{tabular}{l|c|c|c}
\hline CATEGORIA & 1992 & 2002 & DIFERENCIA 1992/2002 \\
\hline Ciudad & 0 & 0 & 0 \\
\hline Pueblo & 1 & 1 & 0 \\
\hline Aldea & 3 & 6 & 3 \\
\hline Caserío & 32 & 19 & -13 \\
\hline Fundo & 49 & 34 & -15 \\
\hline Parcela & 58 & 27 & -31 \\
\hline Parcela de Agrado & 0 & 0 & 0 \\
\hline TOTAL & 143 & 87 & -56 \\
\hline
\end{tabular}

Fuente: Bases de Datos Redatam. Censos 1992 y 2002. (INE) 
Dinámica de cambios en el patrón de asentamiento de la Población Rural: Región del Maule

Población Rural de Romeral concentrada en Entidades Pobladas

La población rural de la comuna de Romeral se concentra principalmente en entidades con categoría de fundo y parcela; esta condición se desprende de la tabla $\mathrm{N}^{\circ} 9$ que muestra que la población rural de la comuna que se concentra en entidades con categoría de aldea o caserío al año 2002 solo equivale al $47 \%$ del total de la población rural de la comuna, cifra que es levemente superior a la del año 1992, en donde los caseríos y aldeas de Romeral concentraban el 46,24\% del total rural.

Tabla N 9: Población Rural de Romeral concentrada en Caseríos y Aldeas

\begin{tabular}{c|c|c|c|c|c|c}
\hline \multirow{2}{*}{ POBLACIÓN } & \multicolumn{3}{|c|}{1992} & \multicolumn{3}{c}{2002} \\
\cline { 2 - 6 } & Total Rural & $\begin{array}{c}\text { En Caseríos y } \\
\text { Aldeas }\end{array}$ & Porcentaje & Total Rura! & $\begin{array}{c}\text { En Caseríos y } \\
\text { Aldeas }\end{array}$ & Porcentaje \\
\hline Hombres & 4.846 & 2.236 & 46,14 & 4.783 & 2.178 & 45,5 \\
\hline Mujeres & 4.169 & 1.936 & 46,43 & 4.249 & 2.068 & 48,6 \\
\hline TOTAL & 9.015 & 4.169 & 46,24 & 9.032 & 4.246 & 47,0 \\
\hline
\end{tabular}

Fuente: Bases de Datos Redatam. Censos 1992 y 2002. (INE)

En cuanto a la población residente en villorrios en la comuna, ésta fue estimada de la misma forma que en la comuna de Curicó, obteniéndose que 374 habitantes rurales residen en villorrios agrícolas en esta comuna (Tabla $\mathrm{N}^{\circ} 10$ ).

\section{Tabla N¹0: Población en Villorrios, Comuna de Romeral}

\begin{tabular}{l|c}
\hline Viviendas en Villorrios & 68 \\
\hline Habitantes por Viviendas (P) & 5.5 \\
\hline Población Villorrios (E) & 374 \\
\hline
\end{tabular}

Fuente: Elaboración propia sobre la base de Encuesta aplicada en terreno (2002). $\mathrm{P}=$ Promedio de Habitantes por vivienda. E= Estimación de población.

En Romeral, la población estimada de los villorrios solo representa un $4,14 \%$ de la población rural total y un $8,8 \%$ de la población rural concentrada en caseríos y aldeas, lo que se debe a que en esta comuna solo existen 4 villorrios rurales (Tabla $\mathrm{N}^{\circ} 11$ ).

\section{Tabla N011: Participación de la población de los villorrios de la Comuna de Romeral}

\begin{tabular}{l|c}
\hline Sobre la población & Porcentaje \\
\hline Rural Total & 4,14 \\
\hline En Caserios y Aldeas & 8,8 \\
\hline
\end{tabular}

Fuente: Elaboración propia sobre la base de Censo de Población y Vivienda (INE 2002).

Identificación de los Villorrios de Romeral en los Censos de Población y Vivienda de 1992 y 2002

Según la Base de Datos Redatam de 1992, la población de Romeral estaba distribuida en 34 localidades pobladas dentro de las que se ubican 143 entidades. De las 34 localidades existentes al año 1992, la mitad, es decir 17, poseían entidades con categoría de aldea o caserío.

Al censo del año 2002, Romeral cuenta con 32 localidades, 2 menos que en el censo de 
1992, que albergan un total de 87 entidades, 56 menos que en el censo anterior. Pese a que en número disminuyen, la cantidad de localidades que concentran entidades con categoría de aldea y caserío se mantiene en 17.
En cuanto al año de formación de los villorrios de la comuna, éste se muestra en la tabla $\mathrm{N}^{\circ} 12$, de la cual se desprende que pese a ser solo cuatro villorrios, estos surgen en años distintos, por lo que hay tanto villorrios antiguos como nuevos.

Tabla N ${ }^{\circ} 12$ : Año de antigüedad de los Villorrios de Romeral

\begin{tabular}{c|c}
\hline Nombre del Villorrio & Año de Formación \\
\hline La Araucaria & 1985 \\
\hline Luxemburgo & 1985 \\
\hline Guaico I & 1995 \\
\hline El Ángel & 2000 \\
\hline
\end{tabular}

Fuente: Encuesta aplicada en terreno (2002).

De acuerdo al año de formación de los villorrios, en el censo de 1992 deberían aparecer solo dos, que corresponden a La Araucaria y Luxemburgo, y en el censo del 2002 deberían encontrarse los cuatro villorrios como entidades independientes.

Figura $N^{\circ}$ 4: Mapa de Villorrios Agrícolas de Romeral según Censos de 1992 y 2002

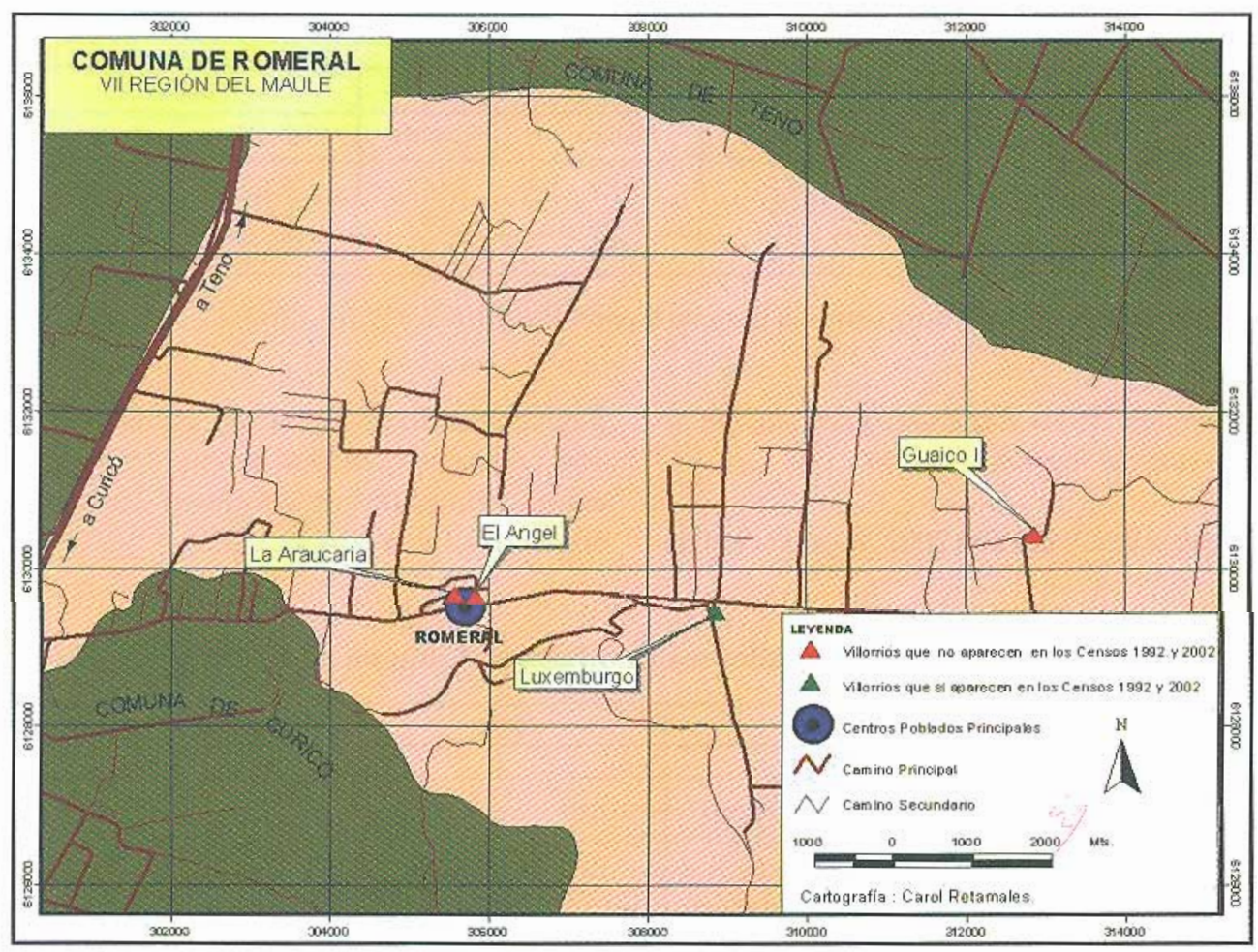

Fuente: Elaboración propia sobre la base de información INE, (1992 y 2002). 
La figura $\mathrm{N}^{\circ} 4$ muestra que tanto en el censo de 1992 como en el del 2002, el único villorrio considerado como entidad independiente corresponde al villorrio Luxemburgo y en ambos censos posee categoría de caserío.

En situación de fusión rural aparece el villorrio Guaico I que en 1992 no existía, pero que en el censo del 2002 fue considerado como parte de la aldea Guaico I Sur conformada con anterioridad al censo de 1992.

El villorrio La Araucaria ya en 1992 fue considerado como parte del pueblo de Romeral, por lo que se encuentra en situación de absorción tanto en ese censo como en el del año 2002. Por su parte, el villorrio El Ángel que surge con posterioridad al censo de 1992, fue también absorbido por el pueblo de Romeral, de esta forma en el censo del 2002 aparece como parte de él.

Independientemente del año de formación, los villorrios de la comuna se sitúan en los alrededores de la capital comunal, lo cual da como resultado en los villorrios de la comuna un patrón de localización puntual, dos de ellos en torno al pueblo de Romeral.

\section{Comuna de Sagrada Familia}

\section{Evolución de la población Rural Comuna de Sagrada Familia}

En la tabla $\mathrm{N}^{\circ} 13$ se aprecia que la población rural de la comuna es altamente superior a la población urbana y supera en todo el periodo el $67 \%$ de la población total.

Llama la atención el periodo intercensal 1982-1992, ya que en este periodo la población total de la comuna experimentó una leve disminución, sin embargo, la población rural muestra una tendencia al aumento en términos generales, y precisamente en este periodo experimenta el crecimiento más significativo.

Tabla N 13: Evolución de la Población Rural de la Comuna de Sagrada Familia

\begin{tabular}{|c|c|c|c|c|c|c|}
\hline \multirow[t]{2}{*}{ AÑO } & \multicolumn{2}{|c|}{ RURAL } & \multicolumn{2}{|c|}{ URBANA } & \multicolumn{2}{|c|}{ TOTAL } \\
\hline & Número & Porcentaje & Número & Porcentaje & Número & Porcentaje \\
\hline 1982 & 11.376 & 67.2 & 5.551 & 32.8 & 16.927 & 100 \\
\hline 1992 & 12.452 & 73.7 & 4.442 & 26.3 & 16.894 & 100 \\
\hline 2002 & 12.439 & 71.0 & 5.080 & 29.0 & 17.519 & 100 \\
\hline
\end{tabular}

Fuente: Elaboración propia sobre la base de Censo 1982,1992 y 2002. (INE)

Evolución de las Entidades Pobladas de la Comuna de Sagrada Familia

Según el censo del año 2002, la población de
Sagrada Familia se distribuye en un total de 166 entidades pobladas, lo cual indica que entre 1992 y 2002 se generaron 26 nuevas entidades (Tabla $\mathrm{N}^{\circ} 14$ ).

Tabla N 14: Número de Entidades según categoría, Comuna de Sagrada Familia

\begin{tabular}{l|c|c|c}
\hline CATEGORÍA & 1992 & $\mathbf{2 0 0 2}$ & DIFERENCIA 1992/2002 \\
\hline Pueblo & 2 & 2 & 0 \\
\hline Aldea & 4 & 11 & 7 \\
\hline Caserío & 18 & 26 & 8 \\
\hline Fundo & 68 & 68 & 0 \\
\hline Parcela & 48 & 57 & 9 \\
\hline Parcela de Agrado & 0 & 2 & 2 \\
\hline TOTAL & 140 & 166 & 26 \\
\hline
\end{tabular}

Fuente: Bases de Datos Redatam. Censos 1992 y 2002. (INE) 
En Sagrada Familia el tipo de poblamiento predominante corresponde a los fundos $y$ parcelas que son las categorías de entidades que concentran un mayor número. Sin embargo, las categorías aldeas y caseríos son las entidades que para objeto de este estudio revisten mayor importancia, ya que dadas las características de poblamiento que las originan, es dentro de estas entidades donde se encuentran los villorrios rurales. La tabla $N^{\circ} 14$ evidencia que entre 1992 y 2002 se generaron 7 nuevas aldeas y 8 nuevos caseríos en la comuna. En ambos censos, la comuna presenta sólo dos entidades urbanas, que corresponden a los pueblos de Sagrada Familia (capital comunal) y Villa Prat.
Población Rural de Sagrada Familia concentrada en Entidades Pobladas

La población que concentran los caseríos y aldeas ha aumentado considerablemente, ya que tal como se muestra en la tabla $N^{\circ} 15$, en 1992 la población que se concentraba en estas categorías equivalía al $38.9 \%$ del total de población rural y en 10 años, es decir, según el censo de 2002, la población que concentran los caseríos y aldeas equivale a un $72.9 \%$ del total de población rural.

Tabla N ${ }^{\circ}$ 15: Población Rural de Sagrada Familia concentrada en Caserios y Aldeas

\begin{tabular}{c|c|c|c|c|c|c}
\hline \multirow{2}{*}{ POBLACIÓN } & \multicolumn{3}{|c|}{1992} & \multicolumn{3}{c}{2002} \\
\cline { 2 - 6 } & Total Rural & $\begin{array}{c}\text { En Caserios y } \\
\text { Aldeas }\end{array}$ & Porcentaje & Total Rural & $\begin{array}{c}\text { En Caseríos y } \\
\text { Aldeas }\end{array}$ & Porcentaje \\
\hline Hombres & 6.654 & 2.499 & 37,6 & 6.515 & 4.689 & 72,0 \\
\hline Mujeres & 5.798 & 2.350 & 40,5 & 5.924 & 4.382 & 74,0 \\
\hline TOTAL & 12.452 & 4.849 & 38,9 & 12.439 & 9.071 & 72,9 \\
\hline
\end{tabular}

Fuente: Bases de Datos Redatam. Censos 1992 y 2002. (INE)

Tal como lo muestra la tabla $\mathrm{N}^{\circ} 16$, la población estimada en los villorrios de Sagrada Familia equivale a 5.428 habitantes.

La población estimada en los villorrios de
Sagrada Familia representa un $43,63 \%$ de la población rural total y más de la mitad $(59,8 \%)$ de la población rural concentrada en entidades con categoría de aldea o caserío (Tabla $N^{\circ} 17$ ).

Tabla N¹6: Población en Villorrios, Comuna de Sagrada Familia

\begin{tabular}{l|c}
\hline Viviendas en Villorrios & 987 \\
\hline Habitantes por Viviendas $(\mathrm{P})$ & 5.5 \\
\hline Pobiación Villorrios $(\mathrm{E})$ & 5.428 \\
\hline
\end{tabular}

Fuente: Elaboración propia sobre la base de Encuesta aplicada en terreno (2002).

$\mathrm{P}=$ Promedio de Habitantes por vivienda. E= Estimación de población.

Identificación de los Villorrios de Sagrada Familia en los Censos de Población y vivienda de 1992 y 2002

Para el censo de 1992, en Sagrada Familia existían un total de 24 localidades y 140 entidades pobladas. De las 24 localidades existentes a esa fecha, 12 están en la categoría de aldea o caserío.
Al año 2002 el número de localidades de la comuna se mantuvo en 24 , pero las entidades pobladas aumentan a 166 y las localidades con aldeas y caseríos a 15 .

La tabla No 18 muestra el año de antigüedad de los villorrios de Sagrada Familia; de ella se desprende que solo 14 de los 30 villorrios existentes en la comuna tienen menos de 10 
años de antigüedad y que por lo tanto, el proceso de formación de villorrios en la comuna se origina hace más de una década atrás.

De acuerdo al año de formación de los villorrios, en el censo de 1992 deberían encon- trarse 9 villorrios agrícolas en la categoría de caserío o aldea, pero la figura $N^{\circ} 5$ muestra que solo fueron considerados 6 , que corresponden a Rincón de Mellado, La Victoria 1, Santa Emilia, Ulises Correa, Corral de Piedra y la Cruz.

Tabla N ${ }^{\circ} 18$ : Año de antigüedad de los Villorrios de Sagrada Familia

\begin{tabular}{cc|cc}
\hline Nombre del Villorrio & Año de Formación & Nombre del Villorrio & Año de Formación \\
\hline Santa Emilia & 1986 & San Sebastián & 1995 \\
\hline Santa Ana 1 & 1988 & Villa Carlos Condell & 1996 \\
\hline Santa Ana 2 & 1990 & Villa La Estrella & 1996 \\
\hline Rincón de Meliado & 1991 & Higuerillas & 1996 \\
\hline La Victoria 1 & Parroncillo & 1996 \\
\hline La Unión & 1991 & Villa Nogalada & 1996 \\
\hline Ulises Correa & 1991 & Santa Ana 4 & 1997 \\
\hline Corral de Piedra & 1991 & Valle Verde & 1997 \\
\hline La Cruz & 1991 & Santa Maria & 1998 \\
\hline La Victoria 2 & 1991 & Santa Ana 3 & 1998 \\
\hline El Bosque & 1993 & Diego Portales & 2000 \\
\hline San José de Peteroa & 1994 & Villa Las Delicias & 2002 \\
\hline Renacer & 1994 & Nuevo Amanecer & 2002 \\
\hline Sanatorio & 1994 & Juan XXIII & 2004 \\
\hline Padre Hurtado & 1994 & Pablo Neruda & 2004 \\
\hline
\end{tabular}

Fuente: Elaboración propia sobre la base de Entrevistas (2005).

Figura $\mathrm{N}^{\circ}$ 5: Villorrios Agrícolas de Sagrada Familia según Censo de 1992

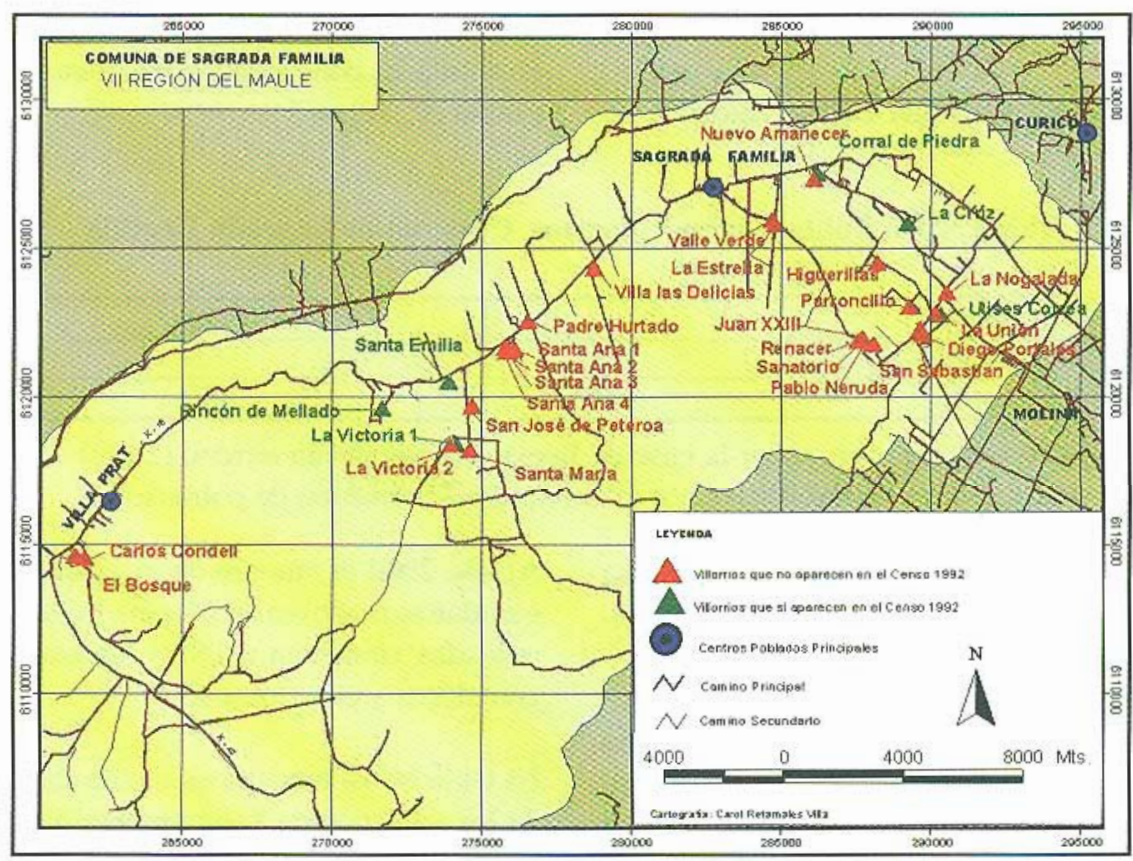

Fuente: Elaboración propia sobre la base de información INE (1992). 
En el censo del 2002 debería aparecer un total de 26 villorrios agrícolas, según el año de formación de estos asentamientos, pero la figura $N^{\circ} 6$ muestra que solo fueron considerados por el Instituto Nacional de Estadísticas
11 villorrios como entidades independientes, los que corresponden a Rincón de Mellado, San José de Peteroa, Santa María, Santa Emilia, Villa las Delicias, Valle Verde, Villa La Estrella, Higuerillas, Parroncillo, Corral de Piedra y La Cruz.

\section{Figura $N^{\circ}$ 6: Mapa de Villorrios Agrícolas de Sagrada Familia según Censo de 2002}

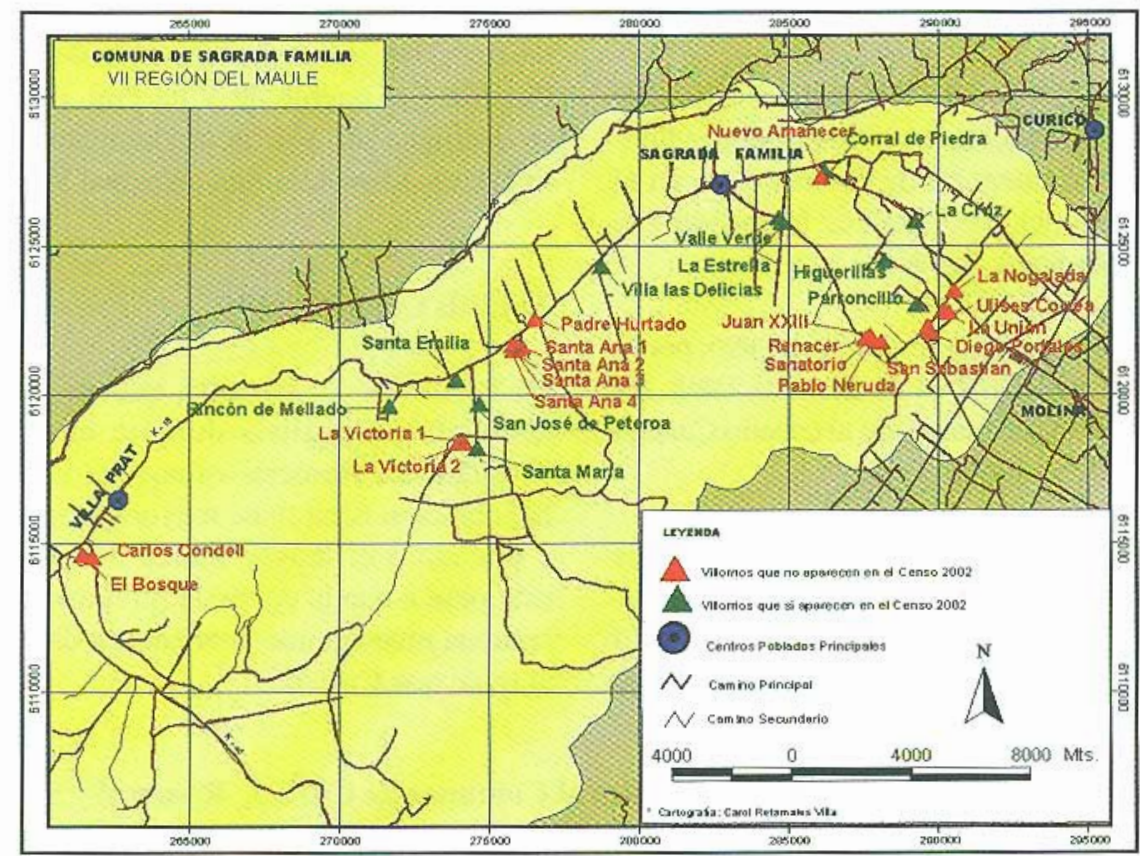

Fuente: Elaboración propia sobre la base de información INE (2002).

Los casos de fusión rural detectados en la comuna corresponden a los siguientes:

- La Victoria 1: en el censo de 1992 este asentamiento fue considerado como una entidad independiente con categoría de caserío. Posterior a este censo surge el villorrio La Victoria 2, que se fusiona con La Victoria 1 y forma la entidad La Victoria en categoría de caserío en el censo del 2002.

- El villorrio Padre Hurtado en 1992 no existía, pero en el 2002 fue considerado como parte de la aldea Santa Carmen/ Santa Ana, pese a que este villorrio está separado físicamente de esta entidad por la Ruta K-16.
- Los villorrios Santa Ana 1 y 2 en el censo de 1992 forman el caserío Santa Ana. En el 2002 estos villorrios forman parte de la aldea Santa Carmen/ Santa Ana.

- Santa Ana 3 y Santa Ana 4 surgen con posterioridad al censo de 1992 y en el 2002 fueron considerados como parte de la aldea Santa Carmen/ Santa Ana.

- Los villorrios Renacer y San Francisco en 1992 no existían y en el 2002 aparecen como parte de la aldea Sanatorio. Cabe destacar que posterior al censo del 2002 surgen aledaños a esta aldea los villorrios Juan XXIII y Pablo Neruda, por lo que es de suponer que en el próximo censo, estos serán considerados también 
como parte de la aldea Sanatorio.

- El villorrio La Unión aparece en ambos censos como parte de la aldea Santa Rosa.

- Los villorrios San Sebastián y Diego Portales surgen con posterioridad al censo de 1992 y en el 2002 fueron considerados como parte de la aldea Santa Rosa.

- El villorrio Ulises Correa en 1992 fue considerado como entidad independiente con categoría de caserío, pero en el censo del 2002 aparece fusionado a la aldea Santa Rosa.

- Villa Nogalada se forma en 1996 , por lo que no existía en el censo de 1992. En el 2002 fue fusionado al caserío Cancha de Rescoldo.

En situación de absorción: los únicos casos de absorción detectados en la comuna corresponden a los Villorrios Carlos Condell y El Bosque, que se forman con posterioridad al censo de 1992 y que en el censo del año 2002 fueron considerados como parte del pueblo de Villa Prat.

La situación anterior determina que en la comuna exista un patrón de localización mixto, en donde se distinguen claramente dos sectores: el primero, entre el acceso a la comuna y el pueblo de Sagrada Familia, en donde se aprecia un patrón de localización areal y el segundo, entre el pueblo de Sagrada Familia y el pueblo de Villa Prat, en donde se distingue un patrón predominantemente lineal, en torno a la ruta principal K-16.

\section{Análisis Comparativo}

La figura $\mathrm{N}^{\circ} 7$ muestra que de las tres comunas en análisis durante el periodo considerado, Romeral es aquella en donde la población rural tiene mayor participación y por tanto el mayor índice de ruralidad, esto pese a que la curva de ruralidad de esta comuna muestra una tendencia a disminuir, al igual que Curicó.

Figura $N^{0}$ 7: Evolución de la Población Rural Comunas de Curicó, Romeral y Sagrada Familia

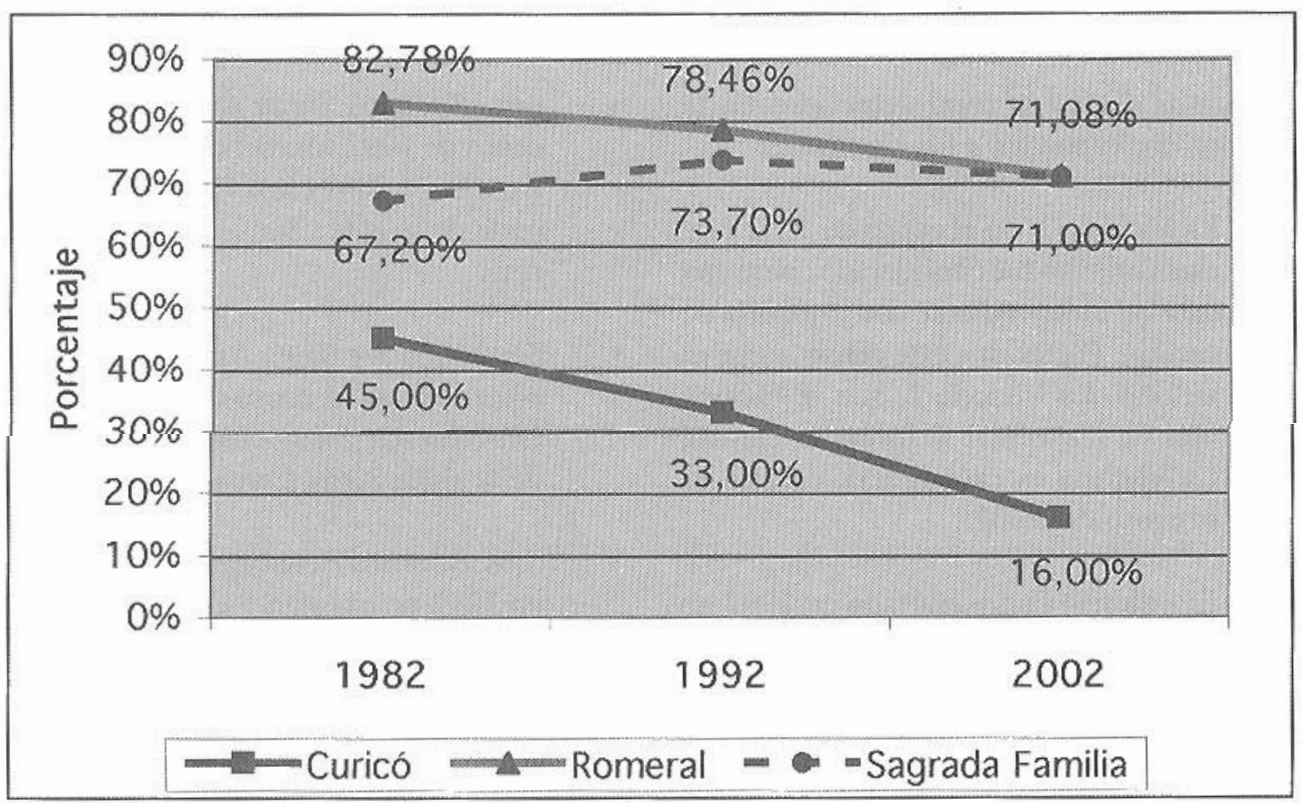

Fuente: Censos de población y vivienda 1982,1992 y 2002 (INE). 
Sagrada Familia ocupa el segundo lugar en cuanto a la participación de la población rural dentro del total comunal. En esta comuna la curva muestra una tendencia al aumento al comienzo del periodo y a la estabilización de la población rural a partir de 1992. Al final del periodo el índice de ruralidad prácticamente iguala la ruralidad de Romeral.

Curicó corresponde a la comuna en donde la población rural tiene menor participación durante todo el periodo. La curva de ruralidad de esta comuna muestra una clara y fuerte tendencia a decrecer alcanzando solo el 16\% en el último censo.

En términos de población absoluta sin embargo, y considerando que la tendencia general en Chile y América Latina es a la reducción de la población rural frente al avance de la urbanización, se puede decir que solo en Curicó esta tendencia se presenta claramente marcada, mientras que en Sagrada Familia y Romeral se produce una situación atípica, determinada por la estabilización de la población rural, aunque proporcionalmente pierde importancia.

Dado que los villorrios agrícolas son asimilados a las entidades rurales con categoría de caserío y aldea, es conveniente señalar el porcentaje de la población rural de las comunas que está concentrado en este tipo de entidades. Al respecto, la figura $\mathrm{N}^{\circ} 8$ muestra que pese a que Romeral es la comuna con mayor ruralidad, el porcentaje de esta población concentrada en caseríos y aldeas es menor que en las otras dos comunas, no superando el $50 \%$ durante todo el periodo considerado.

Figura $N^{\circ}$ 8: Población Rural Concentrada en Caseríos y Aldeas Comunas de Curicó, Romeral y Sagrada Familia

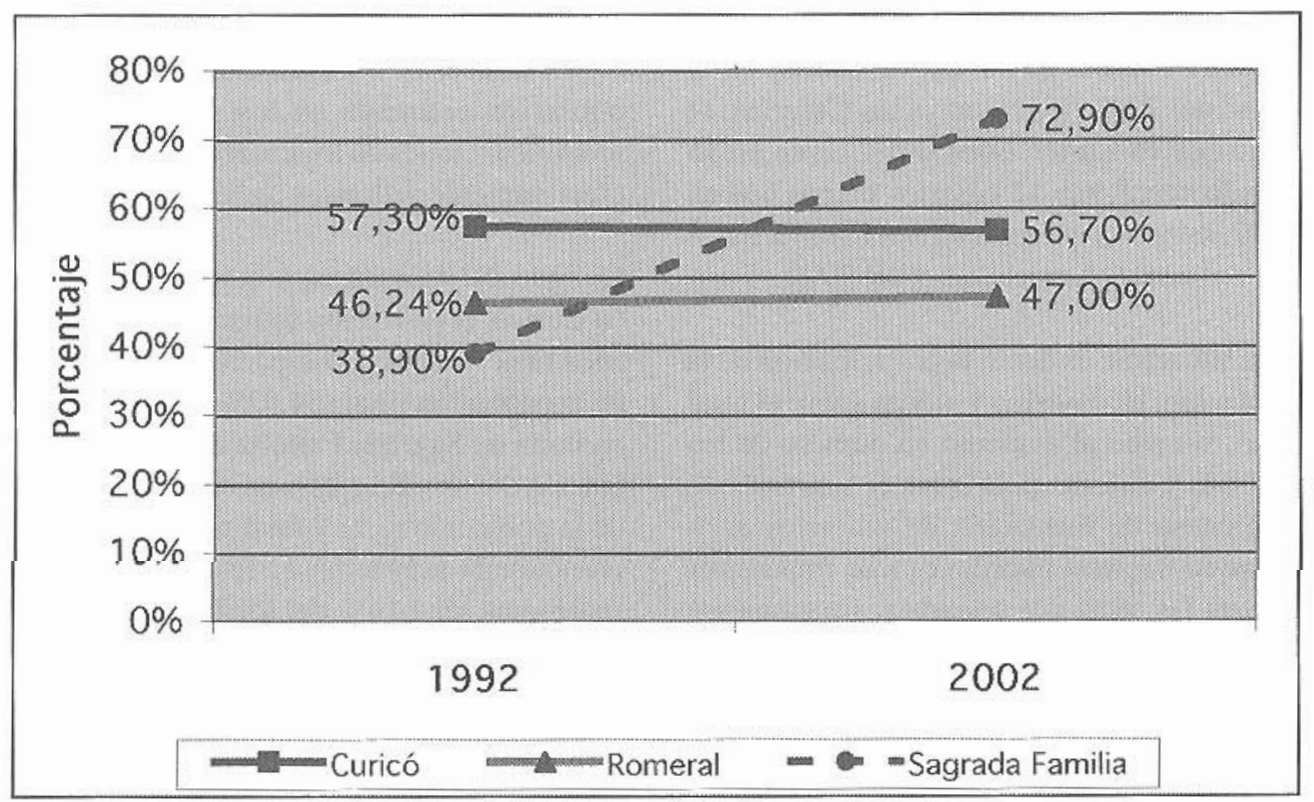

Fuente: Bases de datos Redatam Censos 1992 y 2002 (INE). 
En Curicó, a pesar de ser la comuna con el más bajo índice de ruralidad, la población concentrada en caseríos y aldeas es más del $50 \%$ de la población rural total.

Un caso especial es el que se presenta en Sagrada Familia, en donde el porcentaje de la población rural que se concentra en caseríos y aldeas experimentó un considerable aumento, pasando de un $38,9 \%$ en 1992 a un $72,9 \%$ en el 2002.

Por otro lado, se observa que solo en Sagrada Familia el número de entidades pobladas aumenta entre 1992 y 2002, en Curicó disminuyen las entidades en 69 y en Romeral la disminución de entidades alcanza a 56 (Tabla $\mathrm{N}^{\circ} 19$ ).

Tabla N 19: Evolución de las Entidades Pobladas Comunas de Curicó, Romeral y Sagrada Familia

\begin{tabular}{l|c|c|c}
\hline \multirow{2}{*}{ CATEGORIA } & Curicó & Romeral & Sagrada Familia \\
\cline { 2 - 4 } & Diferencia 1992/2002 & Diferencia 1992/2002 & Diferencia 1992/2002 \\
\hline Ciudad & 0 & 0 & 0 \\
\hline Pueblo & 2 & 0 & 0 \\
\hline Aldea & 4 & 3 & 7 \\
\hline Caserío & -55 & -13 & 8 \\
\hline Fundo & 1 & -15 & 0 \\
\hline Parcela & -23 & -31 & 9 \\
\hline Parcela de Agrado & 2 & 0 & 2 \\
\hline TOTAL & -69 & -56 & 26 \\
\hline
\end{tabular}

Fuente: Bases de Datos Redatam. Censos 1992 y 2002. (INE)

Si bien en las tres comunas consideradas surgen nuevas aldeas, en Curicó se forman solo 4 y en Romeral 3, mientras que en Sagrada Familia hay 7 nuevas aldeas en el censo del 2002. En cuanto a los Caseríos, se tiene que en Curicó éstos disminuyen en 55 y en Romeral hay 13 caseríos menos que en 1992, mientras que en Sagrada Familia hay 8 nuevos caseríos en el censo del 2002.

Esta situación, es decir, la participación de la población en caseríos y aldeas sobre el total rural, sumado al aumento en número de los caseríos y aldeas, podría hacer suponer que el proceso de formación de villorrios agrícolas en Sagrada Familia es más importante que en las otras dos comunas, sin embargo, es necesario considerar que no todos los caseríos y aldeas de las comunas corresponden efectivamente a villorrios agrícolas. $\mathrm{De}$ aquí entonces la necesidad de considerar la población estimada en los villorrios y de identificar cuales de los caseríos y aldeas son efectivamente villorrios agrícolas.

La figura $\mathrm{N}^{\circ} 9$ muestra que comparativamente en Curicó, la población estimada en los villorrios tiene mayor participación sobre el total de la población rural $(54,82 \%)$, seguida de la comuna de Sagrada Familia en donde la población de los villorrios representa un $43,63 \%$ de la población rural y finalmente Romeral, en donde la población de los villorrios solo representa un $4,14 \%$ del total rural. 
Figura $N^{\circ}$ 9: Población Estimada en los Villorrios, sobre el total Rural Comunas de Curicó, Romeral y Sagrada Familia

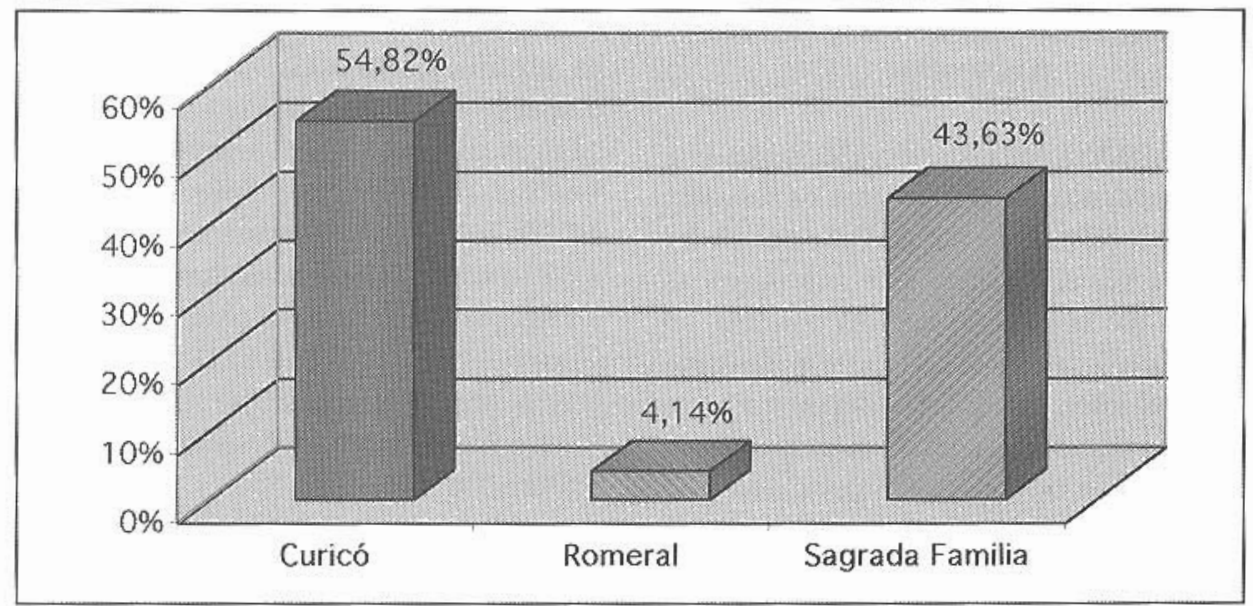

Fuente: Estimación sobre la base de Encuestas aplicadas en terreno (2002 y 2005).

Por su parte, la población estimada en villorrios representa un $96,67 \%$ de la población rural en caseríos y aldeas en la comuna de Curicó, en Sagrada Familia alcanza el 59,8\%, mientras que en Romeral solo equivale a un $8,8 \%$ de la población rural concentrada en aldeas y caseríos (Figura $\mathrm{N}^{\circ} 10$ ).

Figura $\mathrm{N}^{\circ}$ 10: Participación de la población en Villorrios, sobre la población rural concentrada en Caseríos y Aldeas. Comunas de Curicó, Romeral y Sagrada Familia

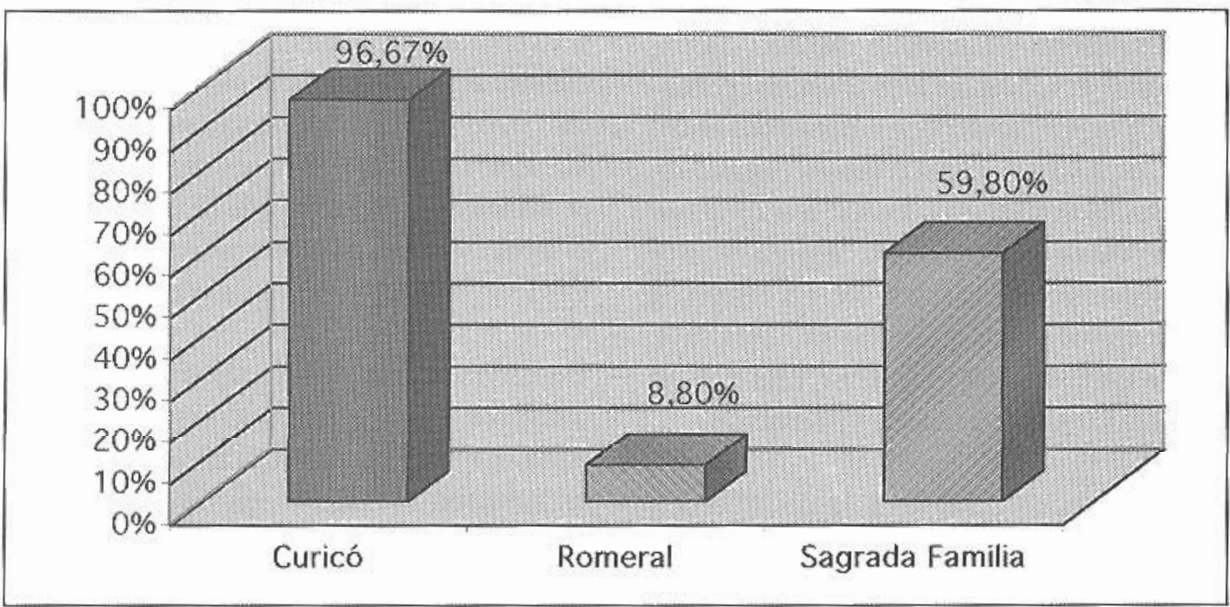

Fuente: Estimación sobre la base de Encuestas aplicadas en terreno (2002 y 2005). 


\section{DISCUSIÓN DE RESULTADOS}

\section{Evolución de la Población Rural e Incidencia en ella de los Villorrios Agrícolas.}

Los resultados del estudio evidencian que es posible distinguir dos tendencias respecto de la evolución de la población rural en las comunas seleccionadas. Por una parte, se observa que si bien en las tres comunas el peso relativo de la población rural desciende a nivel intercensal, hay diferencias entre ellas, por cuanto la tendencia descendente es sostenida a través de los tres Censos en las comunas de Curicó y Romeral, (aunque con más fuerza en Curicó), mientras que en Sagrada Familia ésta es fluctuante, con un alza en 1992 con respecto a 1982, y un leve descenso posterior en 2002 , pero se mantiene una proporción mayor al año de inicio del análisis. Otra diferencia se expresa en términos absolutos de población, ya que mientras en Curicó el descenso es significativo (de aproximadamente 39.000 a 19.000 ), en las otras comunas la población rural tiende a la estabilización entre 1982 y 2002 a pesar de la reducción porcentual.

Esto podría significar que en la comuna de Curicó (predominantemente urbana) pierde importancia el sector rural en términos poblacionales, por ser capital comunal cuyo centro (ciudad de Curicó) ejerce mayor atracción para quienes tienen propensión a migrar, en tanto las otras dos comunas siguen siendo predominantemente rurales, con un centro en la categoría de pueblo que no se constituye en punto de atracción para vivir, mientras el sector rural logra retener a su población.

Por otra parte, en relación a la distribución de la población rural, se observan grandes diferencias entre Curicó y Romeral por una parte y Sagrada Familia por otra. Considerando primeramente las entidades pobladas rurales registradas en los dos últimos censos, las dos primeras comunas reducen significativamente su número total en 69 y 56 entidades respectivamente, mientras que en Sagrada Familia aumentan en 26.
Con respecto a la relación entre población rural dispersa y población rural concentrada en Caseríos y Aldeas, una nueva diferenciación se establece entre las comunas. Si bien en términos absolutos, la población rural dispersa disminuye en las tres comunas, aunque más significativamente en Sagrada Familia (de 7.603 a 3.368) y Curicó (de 10.134 a 8.258), y levemente Romeral (de 4.846 a 4.786), la población rural concentrada en Aldeas y Caseríos se reduce también en Curicó (de 13.636 a 10.821 ) pero aumenta levemente en Romeral (de 4.169 a 4.246) y muy fuertemente en Sagrada Familia (de 4.849 a 9.071 ).

Esto significa por tanto, que si bien en las tres comunas la población rural concentrada es mayor que la dispersa, Sagrada Familia se destaca porque el incremento es evidentemente más significativo entre los dos censos, no existiendo por tanto una tendencia similar entre las dos comunas ruralizadas.

Respecto a la incidencia de los villorrios en la población rural de la comuna, en primer lugar, las comunas de Curicó y Sagrada Familia presentan un número similar de villorrios conformados a través del Programa de Subsidio Rural ( 29 y 30 respectivamente) en relación a Romeral (4), pero la antigüedad de estos asentamientos es mayor en Curicó (27 antes de 1996 y sólo 2 construidos en los últimos 10 años), mientras que en Sagrada Familia la relación es de 16 a 14, lo que indica que el proceso está relativamente estancado en Curicó y vigente en Sagrada Familia.

Considerando la proporción de la población residente en los villorrios con respecto al total rural comunal, en Curicó alcanza el 54,82\% en relación al 43,63\% en Sagrada Familia, diferencia que se acentúa si se relaciona sólo con la población rural concentrada en caseríos y aldeas donde son clasificadas censalmente los villorrios, por cuanto en Curicó la población de los villorrios representa el 96,67\% versus el 59,80 en Sagrada Familia.

Sin embargo, si se considera que el proceso es más reciente en esta última comuna, es 
posible que esa proporción aumente en las estadísticas futuras. Lo que si es similar en ambas comunas, es que el aporte de los villorrios en el proceso.de concentración de la población rural es muy relevante, mientras que en Romeral esto es evidentemente menor, puesto que la presencia de villorrios agrícolas del Subsidio Habitacional del Estado es reducido a la fecha.

Respecto al patrón de localización de los villorrios, entre las tres comunas de análisis Curicó es aquella en donde la antigüedad de estos núcleos es mayor y en donde se manifiesta más claramente un patrón disperso de localización espacial de los villorrios en el territorio comunal.

En Sagrada Familia por su parte, los villorrios más antiguos se localizan como núcleos de población dispersos en la comuna. Sin embargo, el surgimiento de nuevos villorrios aledaños a los ya existentes o en las cercanías de los pueblos ha determinado dos áreas distintas de concentración espacial: la primera de ellas entre el acceso a la comuna y el pueblo de Sagrada Familia, en donde los villorrios presentan un patrón de localización areal y la segunda, entre el pueblo de Sagrada Familia y el Pueblo de Villa Prat en donde los villorrios muestran un patrón de localización lineal en torno al eje principal de transporte comunal, constituido por la Ruta K-16.

Un caso especial corresponde a la Comuna de Romeral, en donde solo existen 4 villorrios agrícolas que se sitúan en las cercanías del pueblo de Romeral, determinando para esta comuna un patrón de localización puntual de estos núcleos.

Por otra parte, una tendencia observable en las tres comunas es la fusión o absorción de villorrios por parte del Instituto Nacional de Estadística, considerando como criterio determinante la proximidad geográfica en general, aunque hay casos curiosos en que esto no corresponde (Padre Hurtado en Sagrada Familia).
En Curicó se detectan 14 fusiones y 1 absorción (al pueblo de Los Niches); en Romeral 1 fusión y 1 absorción (al pueblo de Romeral) y en Sagrada Familia 14 fusiones y 2 absorciones (al pueblo de Villa Prat). Esto significa que muchos villorrios han perdido su nombre original y en los casos de fusión su categoría inicial de asentamiento rural para ser parte de un pueblo en la categoría de urbano, aunque en ambos casos, hasta ahora, los pobladores de estos villorrios siguen identificándolos con su nombre original en forma independiente.

\section{CONCLUSIONES}

Los resultados del estudio, demuestran que la evolución y situación actual de la población rural es heterogénea entre las tres comunas consideradas en el análisis. Mientras que Curicó ha reducido significativamente su importancia estadística al respecto constituyendo una comuna altamente urbanizada (sólo $16 \%$ de población rural), las otras dos comunas destacan por su alto índice de ruralidad $(71 \%)$.

Sin embargo, si se considera la magnitud del proceso de formación de villorrios agrícolas construidos con el aporte del Subsidio Habitacional del Estado, la ruralidad pareciera no ser un factor que propicie el proceso de re-asentamiento a través de esta estrategia, por cuanto en la comuna de Romeral éste es irrelevante con sólo 4 villorrios, mientras en Curicó es tan significativo como en Sagrada Familia (29 y 30 villorrios respectivamente).

Como resultado de ello, podría afirmarse que el proceso de formación de villorrios explicaría a su vez el proceso de re-asentamiento y concentración de la población rural en entidades como caseríos y aldeas en las comunas de Curicó y Sagrada Familia, en tanto en Romeral, donde la presencia de villorrios es irrelevante predomina aún el patrón disperso tradicional del campo chileno representado por las economías campesinas, pero en la medida que la formación de villorrios se in- 
tensifique en el futuro, esta situación tendería a cambiar y en este sentido, sería pertinente identificar los factores que explican el retardo del proceso en esta comuna, puesto que se trata de una dinámica presente en la mayor parte de las áreas modernizadas del sector rural chileno.

Una explicación posible al respecto, podría ser la especialización temprana de esta comuna en la fruticultura, especialmente en la producción de cerezas por parte de pequeños productores, hecho que habría ocasionado que el proceso de descampesinización en Romeral fuese menos significativo que en las otras dos comunas. Por lo tanto, la cantidad de pobladores rurales sin tierra, que son aquellos a quienes se dirige el programa de postulación colectiva al Subsidio Habitacional Rural, serían menos que en Curicó o Sagrada Familia, determinando de esta forma un bajo número de villorrios en esta comuna.

Por otra parte, el proceso de fusión o absorción que el Instituto Nacional de Estadística está llevando a cabo con determinadas entidades pobladas, como los villorrios, da cuenta de una estrategia para agruparlos conformando asentamientos de mayor tamaño que podrían justificar a futuro la inversión en equipamiento comunitario in situ, aunque ello signifique que algunos de sus componentes pierdan su nombre original y su independencia, e incluso su categoría de entidad rural en el caso de absorción a un pueblo vecino, y en este caso, se daría la paradoja de residencia urbana y trabajo en el sector rural, que incluso a futuro podría reorientarse hacia empleos urbanos. Junto con esto, es posible también que la urbanización de los modos de vida que conlleva la concentración de la población, se acentúe bajo estas circunstancias.

Finalmente, el re-asentamiento de la población rural en núcleos de pequeño tamaño como son los villorrios, implica una modificación del patrón de asentamiento, desde el disperso (que predomina en las áreas tradicionales rurales), hacia el patrón concentrado en la categoría de caserío o aldea (dependiendo de su tamaño demográfico), que es la ten- dencia observada en las áreas modernizadas donde hay presencia de una mayor dinámica de tierras y procesos de descampesinización asociados.

Si se considera la localización espacial de estos villorrios, se constata un predominio del patrón lineal de asentamiento en torno a ejes de caminos rurales, tal como se estructuró durante el proceso de parcelamiento de la Reforma Agraria con respecto a los sitios residenciales, lo cual constituye un aspecto favorable para los pobladores, por cuanto facilita el acceso a medios de transporte público y con ello, a las capitales comunales y al equipamiento de servicios comunitarios situados en estos ejes.

Considerando el referencial bibliográfico, se concuerda con Jordán (1987), respecto a que la modificación del patrón de asentamiento de la población rural está vinculado a procesos más amplios de ocurrencia nacional, como son los de Reforma Agraria y el de Modernización rural, los cuales han transformado significativamente las estructuras del agro chileno.

Sin embargo, los resultados de ambos son diferentes: mientras en el primero se estimuló la campesinización de los trabajadores del agro a través de la propiedad de la tierra (parcelas productivas y sitios residenciales), el proceso de modernización actual ha generado la descampesinización de los propietarios más frágiles (como los parceleros de la Reforma Agraria),y como resultado de lo cual se incrementa el grupo de los pobladores rurales sin tierra productiva, que entre otros, son los que postulan al Subsidio Habitacional Rural del Estado para formar villorrios agrícolas

Por otra parte, el proceso de Urbanización del Campo vigente en Chile presenta una situación dual, considerando los nuevos propietarios de origen urbano y de altos ingresos (conceptualizado como Urbanización de Elite por Armijo, 1997), y los pobladores de bajos ingresos y de origen rural de los villorrios, pero independiente del nivel de urbanización alcanzado, en ambos casos su diseño arqui- 
tectónico y material constructivo no guarda relación con el hábitat tradicional del campo en la zona central del país, proceso que ha sido denominado en el primer caso como Urbanización difusa (Clouth,1987), Neo-ruralismo (García et al, 1995) o Exurbanización (Molinero, 1990), y en el segundo caso como Agrourbanización (Daher,1987).

A su vez, el proceso de concentración de la población rural en villorrios (en la categoría de Caseríos o Aldeas según la clasificación del INE) implica otra nueva dualidad del asentamiento en el espacio rural, considerando que la población dispersa tiende a disminuir a medida que aumenta la población concentrada en núcleos y que esta última ha mejorado objetivamente sus condiciones de vida mediante el acceso a los servicios básicos asociados a la vivienda, en tanto la población dispersa carece en general de ellos, lo que unido a la dinámica del mercado de tierras observado podría estimular aún más el proceso de formación de villorrios, y con ello justificar la tesis descampesinista planteada para el agro latinoamericano, referida a la desaparición gradual del sector campesino frente a los avances de la modernización rural.

Finalmente, el dualismo Intra-rural expresado entre el sector moderno y tradicional del campo chileno, la urbanización de elite y la de pobladores rurales de bajos ingresos y la población concentrada versus la población dispersa del sector rural, ratifica las ideas de Sili (2002) respecto a que esta diferenciación sustituye en importancia a la planteada en la Teoría del Dualismo estructural campo- ciudad, lo que evidencia una revalorización del campo en el contexto del nuevo rol asumido en el proceso de modernización actual, donde la competencia por el espacio rural se plantea entre el uso productivo y el uso residencial del suelo, siendo que este último cobra más importancia a pesar de la normativa existente respecto a la preservación de la áreas de aptitud agrícola, lo que deriva de la inexistencia de una Política de Ordenamiento Territorial Rural en Chile.

\section{REFERENCIAS}

ARMIJO, G., 2000. La faceta rural de la Región Metropolitana: entre la Sub-Urbanización campesina y la Urbanización de Elite. EURE 78, 131-135.

CLOUTH, H., 1976. Geografía Rural. Ediciones Oikos-Tau. Barcelona, (Traducción), $301 \mathrm{pp}$.

DAHER, A., 1987. Agrourbanización "for export". EURE 41: 7-14.

DE MATTOS, C., 1979. Crecimiento y Concentración Espacial en América Latina: Algunas Consecuencias. EURE, 16: 69-80.

ECHENIQUE, J., 2001. Ruralidad en Chile: Evolución y Proyecciones. En: Perspectivas para la Ruralidad en Chile. Editorial Universidad de Santiago. Santiago, Chile, 51-74 pp.

FERRÃO, J., 2000. Relações entre mundo rural e mundo urbano. Evolução histórica, Situação actual e pistas para o futuro. EURE 78: $1-9$.

GARCÍA, R., et al., 1995. Geografía Rural. Colección Espacio y Sociedad. Editorial Síntesis. Madrid, 235 pp.

HERMOSILLA, E., 1994. El Hábitat Rural es una prioridad del MINVU. En: Vivienda y Participación. Ministerio de Vivienda y Urbanismo. Santiago, Chile: 41 pp.

INSTITUTO GEOGRÁFICO MILITAR (IGM), Cartografía Digital: Comunas de Curicó, Romeral y Sagrada Familia. Santiago, Chile.

INSTITUTO NACIONAL DE ESTADÍSTICA (INE), Censos de Población y Vivienda 1982, 1992 y 2002; Bases de Datos Redatam 1992 y 2002; VI Censo Nacional Agropecuario 1997. Santiago, Chile.

JORDÁN, R., 1987. Los Asentamientos Rurales en América Latina: Algunas Ca- 
racterísticas principales. En: Poblamiento y Vjvienda Rural. Grupo de Investigaciones Agrarias. Academia de Humanismo Cristiano. Santiago, Chile, 10-17 pp.

MOLINERO, F., 1990. Los Espacios Rurales. Agricultura y Sociedad en el Mundo. Editorial Ariel. Barcelona, 430 pp.

RETAMALES, C., 2006. Efectos Socioespaciales derivados de la concentración de la población en Villorrios Agrícolas en el contexto de la Globalización. Comuna de Sagrada Familia- VII Región del Maule. Memoria para optar al Titulo de Geógrafo. Escuela de Geografía, Universidad de Chile. Santiago, Chile, 236 pp., inédito.

RIFFO, M., 1998. Globalización de la Economía e Impacto Espacial en las Áreas Rurales de la Zona Central de Chile. Revista Chilena de Historia y Geografía 164: 157-172.
RIFFO, M. y RETAMALES, C., 2005. Caracterización del Proceso de Re-asentamiento de la Población Rural vinculado a la Globalización de la Economía en la Región del Maule. Anales de la Sociedad Chilena de Ciencias Geográficas. 62-90.

RIVERA, R y CRUZ, M. E; 1984. Pobladores Rurales. Grupo de Investigaciones Agrarias (GIA). Santiago, 222 pp.

ROMERO, H. y TOLEDO, X., 2000. Ecología Urbana y Sustentabilidad Ambiental de las Ciudades Intermedias chilenas. Anales de la Sociedad Chilena de Ciencias Geográficas Santiago, Chile: $445-452$.

SILI, M., 2002. Del Enfoque Agrario al Enfoque Rural. Ideas y Conceptos para construir una nueva ruralidad. Revista Universitaria de Geografía: 71-90. 